\title{
Assessing the internal consistency of the CARINA database in the Indian sector of the Southern Ocean
}

\author{
C. Lo Monaco' , M. Álvarez ${ }^{2}$, R. M. Key ${ }^{3}$, X. Lin ${ }^{3}$, T. Tanhua ${ }^{4}$, B. Tilbrook ${ }^{5}$, D. C. E. Bakker ${ }^{6}$, \\ S. van Heuven ${ }^{7}$, M. Hoppema ${ }^{8}$, N. Metzl ${ }^{1}$, A. F. Ríos ${ }^{9}$, C. L. Sabine ${ }^{10}$, and A. Velo ${ }^{9}$ \\ ${ }^{1}$ LOCEAN-IPSL, Université Pierre et Marie Curie, Paris, France \\ ${ }^{2}$ IMEDEA, CSIC-UIB, Universitat de les Illes Balears, Esporles, Spain \\ ${ }^{3}$ Atmospheric and Oceanic Sciences Program, Princeton University, Princeton, USA \\ ${ }^{4}$ Leibniz-Institut für Meereswissenschaften, Marine Biogeochemie, Kiel, Germany \\ ${ }^{5}$ CSIRO Wealth from Oceans Flagship/ACE-CRC, Hobart, Australia \\ ${ }^{6}$ School of Environmental Sciences, University of East Anglia, Norwich, UK \\ ${ }^{7}$ Department of Ocean Ecosystems, University of Groningen, Groningen, The Netherlands \\ ${ }^{8}$ Alfred Wegener Institute for Polar and Marine Research, Bremerhaven, Germany \\ ${ }^{9}$ Instituto de Investigaciones Marinas - CSIC, Eduardo Cabello 6, Vigo, Spain \\ ${ }^{10}$ NOAA-Pacific Marine Environmental Laboratory, Seattle, USA
}

Received: 8 September 2009 - Published in Earth Syst. Sci. Data Discuss.: 9 October 2009

Revised: 16 December 2009 - Accepted: 4 January 2010 - Published: 5 February 2010

\begin{abstract}
Carbon and carbon-relevant hydrographic and hydrochemical ancillary data from previously not publicly available cruises were retrieved and recently merged to a new data base, CARINA (CARbon IN the Atlantic). The initial North Atlantic project, an international effort for ocean carbon synthesis, was extended to include the Arctic Mediterranean Seas (Arctic Ocean and Nordic Seas) and all three sectors of the Southern Ocean. Of a total of 188 cruises, 37 cruises are part of the Southern Ocean. The present work focuses on data collected in the Indian sector $\left(20^{\circ} \mathrm{S}-70^{\circ} \mathrm{S} ; 30^{\circ} \mathrm{E}-150^{\circ} \mathrm{E}\right)$. The Southern Indian Ocean dataset covers the period 1992-2004 and includes seasonal repeated observations. Parameters including salinity, dissolved inorganic carbon $\left(\mathrm{TCO}_{2}\right)$, total alkalinity (TA), oxygen, nitrate, phosphate and silicate were examined for cruise-to-cruise and overall consistency. In addition, data from an existing, quality controlled data base (GLODAP) were introduced in the CARINA analysis to improve data coverage in the Southern Ocean. A global inversion was performed to synthesize the information deduced from objective comparisons of deep measurements $(>1500 \mathrm{~m})$ at nearby stations (generally $<220 \mathrm{~km}$ ). The corrections suggested by the inversion were allowed to vary within a fixed envelope, thus accounting for ocean interior variability. The adjustments applied to CARINA data and those recommended for GLODAP data, in order to obtain a consistent merged dataset, are presented and discussed. The final outcome of this effort is a new quality controlled data base for $\mathrm{TCO}_{2}$ and other properties of the carbon system that can now be used to investigate the natural variability or stability of ocean chemistry and the accumulation of anthropogenic carbon. This data product also offers an important new synthesis of seasonal to decadal observations to validate ocean biogeochemical models in a region where available historical data were very sparse.
\end{abstract}

Correspondence to: C. Lo Monaco

(claire.lomonaco@locean-ipsl.upmc.fr) 


\begin{tabular}{|c|c|c|c|c|}
\hline $\begin{array}{l}\text { Data Product } \\
\text { Parameter Name }\end{array}$ & $\begin{array}{l}\text { Data Product } \\
\text { Flag Name }\end{array}$ & $\begin{array}{l}\text { Exchange File } \\
\text { Parameter Name }\end{array}$ & $\begin{array}{l}\text { Exchange File } \\
\text { Flag Name }\end{array}$ & Units \\
\hline station & & STANBR & & \\
\hline day & & DATE & & \\
\hline month & & DATE & & \\
\hline year & & DATE & & \\
\hline latitude & & LATITUDE & & decimal degrees \\
\hline $\begin{array}{l}\text { longitude } \\
\text { depth }\end{array}$ & & LONGITUDE & & $\begin{array}{l}\text { decimal degrees } \\
\text { meters }\end{array}$ \\
\hline temperature & & CTDTMP & & ${ }^{\circ} \mathrm{C}$ \\
\hline salinity & sf & SALNTY & SALNTY_FLAG_W & \\
\hline ctdsal & ctdsf & CTDSAL & CTDSAL_FLAG_W & \\
\hline pressure & & CTDPRS & & decibars \\
\hline oxygen & of & OXYGEN & OXYGEN_FLAG_W & micromole $\mathrm{kg}^{-1}$ \\
\hline nitrate & no3f & NITRAT & NITRAT_FLAG_W & micromole $\mathrm{kg}^{-1}$ \\
\hline nitrite & no2f & NITRIT & NITRIT_FLAG_W & micromole $\mathrm{kg}^{-1}$ \\
\hline silicate & sif & SILCAT & SILCAT_FLAG_W & micromole $\mathrm{kg}^{-1}$ \\
\hline phosphate & po4f & PHSPHT & PHSPHT_FLAG_W & micromole $\mathrm{kg}^{-1}$ \\
\hline tco 2 & $\operatorname{tco} 2 f$ & TCARBN & TCARBN_FLAG_W & micromole $\mathrm{kg}^{-1}$ \\
\hline alk & alkf & ALKALI & ALKALI_FLAG_W & micromole $\mathrm{kg}^{-1}$ \\
\hline
\end{tabular}

Table of parameters directly relevant for this overview. For a list of all properties in the CARINA data base see Key et al. (2009).

\section{Data coverage and parameter measured}

Repository-Reference: CARINA.SO.V1.0, doi:10.3334/CDIAC/otg.CARINA.SO.V1.0 http://cdiac.ornl.gov/ftp/oceans/CARINA/CARINA_ Database/CARINA.SO.V1.0/

Available at: http://cdiac.ornl.gov/oceans/CARINA/Carina_inv.html Coverage: $20^{\circ} \mathrm{S}$ to $70^{\circ} \mathrm{S} ; 30^{\circ} \mathrm{E}$ to $150^{\circ} \mathrm{E}$ Location Name: Indian sector of the Southern Ocean Date/Time Start: December 1992

Date/Time End: January 2005

\section{Introduction}

The need for consistent basin-wide data is growing as scientists try to address large-scale issues, not only for observational assessments but also as a validation for large-scale modeling efforts. The availability of accurate historical data is also critical for assessments of temporal changes. A major previous ocean carbon synthesis effort, GLODAP: Global Data Analysis Project (Key et al., 2004; Sabine et al., 2005), primarily evaluated data from the large international WOCE and JGOFS projects conducted in the 1990's. Coincidently, a very large data base of hydrographic, nutrients and oxygen measurements collected during WOCE cruises combined with pre-WOCE historical data was constructed and quality controlled (Gouretski and Jancke, 2001), so that the proposed adjustments could also be applied in GLODAP. The final product was a coherent dataset of carbon and related parameters, publicly available, which has been widely used (e.g., Feely et al., 2002; Mikaloff-Fletcher et al., 2006; McNeil et al., 2007; Mikaloff-Fletcher et al., 2007; Vazquez et al., 2009) and from which major results originated, e.g., estimates of anthropogenic $\mathrm{CO}_{2}$ stored in the ocean (Sabine et al., 2004; Waugh et al., 2006).

More ocean carbon observations were collected since the WOCE-era thanks to international efforts such as the European Integrated Project CARBOOCEAN, as well as many national initiatives. The development of the CARINA data base dedicated to carbon-relevant cruise data from the North Atlantic Ocean was initiated in 1999 as an essentially informal, unfunded project organized by Ludger Mintrop and Doug Wallace (IFM-GEOMAR, Kiel, Germany). It resulted in the assembly of a large collection of previously unavailable carbon data. In 2006, at a meeting in Laugarvatn (Iceland) this effort was strongly intensified under the aegis of the EU project CARBOOCEAN and the International Ocean Carbon Coordination Project (IOCCP). It was decided that the CARINA data synthesis effort should be extended to the whole Atlantic basin, including the Arctic Mediterranean Seas (AMS, which includes the Arctic Ocean and Nordic Seas) and the Southern Ocean. In addition, due to the strong zonal structure of the Southern Ocean, it was considered most efficient to include the entire circumpolar ocean in the new synthesis effort. Reasons for this are the poor coverage of these areas in the previous data synthesis and the recent availability of new data sets. The experience gleaned from the GLODAP effort was invaluable for the success of the CARINA project and therefore we gladly made use of it in the form of reports and publications, but more importantly by involving key people from GLODAP in the CARINA project.

During the initial meeting in Iceland a Southern Ocean Carbon Synthesis (SOCS) group was formed, with three subsequent meetings in Kiel, Germany (March 2007), Delmenhorst, Germany (December 2007) and Paris, France 


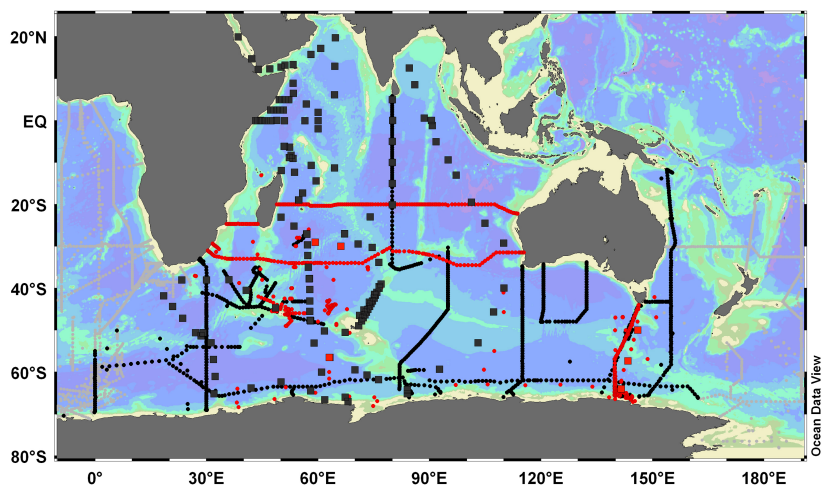

Figure 1. Map of the hydrographic stations where GLODAP and CARINA data were collected. Cruises identified in Table 1 are shown in red for CARINA data (with squares for deep OISO stations). The GLODAP dataset in black includes WOCE lines (circles) and historical data (GEOSECS and INDIGO, squares).

(June 2008) to tune the methodology and evaluate the results. Close contact with the North Atlantic and AMS working groups was maintained throughout the process, both at the above meetings and via separate visits and emails, to ensure that consistent data processing and evaluation was maintained among the groups. Still, each group or sub-group had to deal with specific issues. One important issue for the Southern Ocean was the need for extending the data coverage in order to obtain enough crossover points for all the new cruises to be evaluated, this was achieved by incorporating the Southern Ocean cruise data from GLODAP to the CARINA dataset (i.e. all processing and computations were done with these data as well). In contrast to the North Atlantic and AMS groups, it was considered more efficient to divide the work into three specific Southern Ocean regions, the Atlantic, Indian and Pacific sectors, rather than by parameters.

This paper presents the cross-check analyses performed with CARINA and GLODAP data from the Indian sector of the Southern Ocean. The dataset is presented first, then the cross-check analyses are described by highlighting any divergence from the common procedure and finally the proposed adjustments are presented and discussed.

\section{Data coverage}

The Southern Indian Ocean dataset consists of data collected during cruises conducted fully or partly in the South Indian Ocean (south of $20^{\circ} \mathrm{S}$ ) and the corresponding Antarctic region between $30^{\circ} \mathrm{E}$ and $150^{\circ} \mathrm{E}$ (Fig. 1). This dataset consists of new observations from 21 CARINA cruises (Table 1). These observations were not included in the previous GLODAP synthesis either because they were collected after the 1990 's (14 cruises) or because they were not available at that time (6 cruises conducted between 1992 and 1999). In addi-
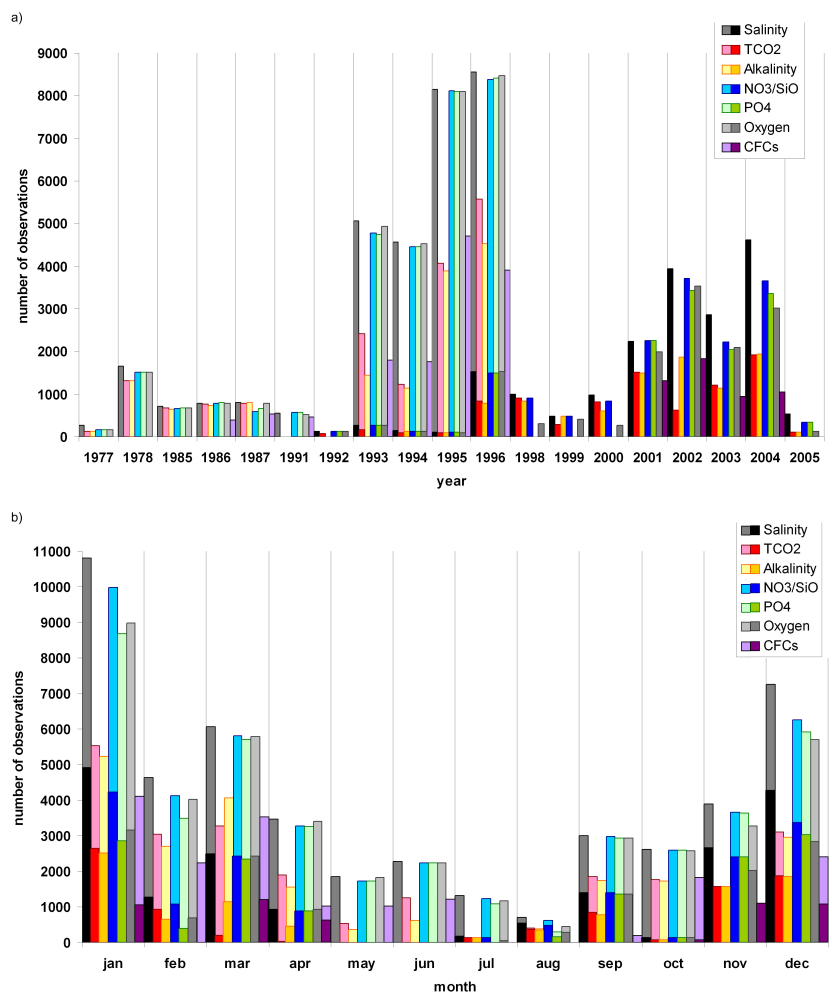

Figure 2. Temporal distribution of the measurements assembled in the Southern Indian dataset (a) by year and (b) by month. For each year or month color bars compare the number of observations for salinity, $\mathrm{TCO}_{2}$, alkalinity, nitrate/silicate, phosphate, oxygen and CFCs. CARINA data (bright colors) are distinguished from GLODAP data (light colors).

tion data from 18 GLODAP cruises were included in the secondary quality control (Table 1 ), most of which have already been evaluated (Key et al., 2004). Here we used the unadjusted data, so that our results can be compared to the adjustments applied in GLODAP (http://cdiac.ornl.gov/oceans/ glodap/Indian.htm). Figure 2 shows the time distribution of the data (year and month of observation). The dataset includes historical data collected at four cruises: GEOSECS (1978), INDIGO1 (1985), INDIGO2 (1986) and INDIGO3 (1987), while all other cruises were conducted after 1990 (mainly over the periods 1993-1996 and 2001-2004). Most of the observations were collected at the summer season (November-March), although about one quarter of the observations were collected in winter both north and south of the Polar Front $\left(\sim 50^{\circ} \mathrm{S}\right)$, mainly during September (Fig. $2 \mathrm{~b}$ ).

The dataset includes information on salinity and oxygen measured at all cruises, as well as nutrients (nitrate, phosphate and silicate) for most of the cruises, dissolved inorganic carbon $\left(\mathrm{TCO}_{2}\right)$ and total alkalinity (TA). In addition, $\mathrm{pH}, p \mathrm{CO}_{2}$ and transient tracer data were also available for a limited number of cruises. However, these observations are too sparse to detect any systematic offset using the crossover 
Table 1. CARINA and GLODAP cruises assembled in the Southern Indian dataset.

CARINA cruises are identified by their cruise number (ID).

\begin{tabular}{|c|c|c|c|c|c|c|}
\hline ID & Cruise expocode & Southern Ocean sector & Date & Ship & Chief scientist & P.I. for $\mathrm{TCO}_{2} / \mathrm{Alk}$ \\
\hline 33 & 09AR19960822 & Indian-Pacific & 8/22-9/21/1996 & A. Australis & S. Rintoul & B. Tilbrook \\
\hline 34 & 09AR20011029 & Indian-Pacific & $11 / 29-2 / 11 / 2001$ & A. Australis & B. Tilbrook & B. Tilbrook, C. Sabine \\
\hline 96 & 35MF19980121 & Indian & $1 / 21-2 / 19 / 1998$ & M.-Dufresne & N. Metzl & C. Lo Monaco \\
\hline 97 & 35MF19980818 & Indian & 8/18-9/9/1998 & M.-Dufresne & N. Metzl & C. Lo Monaco \\
\hline 98 & 35MF19981205 & Indian & $12 / 5-12 / 27 / 1998$ & M.-Dufresne & N. Metzl & C. Lo Monaco \\
\hline 99 & 35MF19990104 & Indian & $1 / 4-2 / 23 / 1999$ & M.-Dufresne & M. Denis & B. Delille, D. Lefèvre \\
\hline 100 & $35 \mathrm{MF} 20000117$ & Indian & $1 / 17-1 / 27 / 2000$ & M.-Dufresne & N. Metzl & C. Lo Monaco \\
\hline 101 & 35MF20000719 & Indian & $7 / 19-8 / 16 / 2000$ & M.-Dufresne & N. Metzl & C. Lo Monaco \\
\hline 102 & $35 \mathrm{MF} 20010103$ & Indian & $1 / 3-1 / 26 / 2001$ & M.-Dufresne & N. Metzl & C. Lo Monaco \\
\hline 103 & 35MF20020104 & Indian & $1 / 4-2 / 1 / 2002$ & M.-Dufresne & N. Metzl & C. Lo Monaco \\
\hline 104 & $35 \mathrm{MF} 20030123$ & Indian-Pacific & $1 / 23-2 / 17 / 2003$ & M.-Dufresne & N. Metzl & C. Lo Monaco \\
\hline 105 & $35 \mathrm{MF} 20040103$ & Indian & $1 / 3-2 / 9 / 2004$ & M.-Dufresne & N. Metzl & C. Lo Monaco \\
\hline 110 & 49HН19941213 & Indian-Pacific & $12 / 13 / 1994-1 / 28 / 1995$ & Hakuho-Maru & K. Kawaguchi, S. Watanabe & M. Ishii \\
\hline 111 & 49HH20011208 & Indian-Pacific & 12/8/2001-1/19/2002 & Hakuho-Maru & M. Terazaki & M. Ishii \\
\hline 114 & 49NZ20031209 & Indian & $12 / 9 / 2003-1 / 24 / 2004$ & Mirai & M. Fukasawa & A. Murata \\
\hline 115 & 49ZS19921203 & Indian-Pacific & $12 / 3 / 1992-3 / 19 / 1993$ & Shirase & N. Sato, R. Maruse & M. Ishii \\
\hline 149 & 61TG20020206 & Indian-Pacific & $2 / 6-3 / 7 / 2002$ & Tangaroa & T. Odate & M. Ishii \\
\hline 150 & $61 \mathrm{TG} 20030217$ & Indian-Pacific & $2 / 17-3 / 12 / 2003$ & Tangaroa & T. Odate & M. Ishii \\
\hline 163 & 74AB20020301 & Indian & $3 / 1-4 / 15 / 2002$ & C. Darwin & H. Bryden & A. Rios, M. Alvarez \\
\hline 174 & 74DI20041103 & Indian & $11 / 3-12 / 10 / 2004$ & Discovery & R. Pollard & D. Bakker \\
\hline \multirow[t]{19}{*}{175} & 74DI20041213 & Indian & $12 / 13 / 2004-1 / 21 / 2005$ & Discovery & R. Sanders & D. Bakker \\
\hline & 06AQ19960317 & Indian-Atlantic & $3 / 17-5 / 20 / 1996$ & Polarstern & E. Fahrbach & M. Hoppema \\
\hline & $35 \mathrm{MF} 19960220$ & Indian-Atlantic & $2 / 20-3 / 22 / 1996$ & M. Dufresne & A. Poisson & A. Poisson \\
\hline & 317519950922 & Indian & 9/22-10/25/1995 & M. Baldridge & R. Molinari & F. Millero \\
\hline & 09FA19941112 & Indian & $11 / 12-12 / 5 / 1994$ & Franklin & M. Tomczak & NA \\
\hline & 74DI19930206 & Indian & 2/6-3/18/1993 & Discovery & R. Dickson & J. Robertson \\
\hline & 74DI19950106 & Indian & $1 / 6-2 / 21 / 1995$ & Discovery & R. Pollard & NA \\
\hline & 74DI19940219 & Indian & 2/19-3/31/1994 & Discovery & R. Dickson & NA \\
\hline & 320619960503 & Indian & $5 / 3-7 / 4 / 1996$ & N. B. Palmer & J. Swift, T. Whitoorth & F. Millero, T. Takahashi \\
\hline & 35MF19930123 & Indian-Atlantic & $1 / 23-3 / 9 / 1993$ & M. Dufresne & A. Poisson & A. Poisson \\
\hline & 316 N19941201 & Indian & $12 / 1 / 1994-1 / 19 / 1995$ & Knorr & M. McCartney, T. Whitworth & D. Wallace \\
\hline & 09AR19941213 & Indian-Pacific & $12 / 13 / 1994-2 / 2 / 1995$ & A. Australis & S. Rintoul & B. Tilbrook \\
\hline & 09AR19930404 & Indian-Pacific & $4 / 4-5 / 9 / 1993$ & A. Australis & S. Rintoul & B. Tilbrook \\
\hline & 09FA19930624 & Indian-Pacific & $6 / 24-7 / 17 / 1993$ & Franklin & J. Church, S. Rintoul & NA \\
\hline & 09AR19910925 & Indian-Pacific & $9 / 25-10 / 27 / 1991$ & A. Australis & S. Rintoul & NA \\
\hline & INDIGO (1985) & Indian & 2/24-3/1985 & M. Dufresne & A. Poisson & A. Poisson \\
\hline & INDIGO (1986) & Indian & $4 / 1-4 / 30 / 1986$ & M. Dufresne & M. Fieux & A. Poisson \\
\hline & INDIGO (1987) & Indian-Atlantic & $1 / 14-2 / 20 / 1987$ & M. Dufresne & N. Metzl & A. Poisson \\
\hline & GEOSECS_IND & GEOSECS (st.403-454) & $12 / 4 / 1977-4 / 24 / 1978$ & Melville & $\begin{array}{l}\text { R. Williams, H. Craig, } \\
\text { R. Weiss, W. Broecker, } \\
\text { D. Spencer }\end{array}$ & $\begin{array}{l}\text { R. Williams, T. Takahashi, } \\
\text { C. Keeling }\end{array}$ \\
\hline
\end{tabular}

method, and only the seven parameters listed in Table 2 are evaluated in this study. The GLODAP and CARINA data are available at the Carbon Dioxide Information Analysis Center (http://cdiac.ornl.gov/oceans/glodap/GlopDV.htm and http://cdiac.ornl.gov/oceans/CARINA/Carina_inv.html). In addition to metadata that documents measurements performed during most of the cruises, a detailed description of the GLODAP and CARINA datasets can be found in Sabine et al. (2005) and Key et al. (2009), respectively, as well as in the other more specialized papers of this special issue.

One important aspect of the cruises conducted in the Southern Indian Ocean is their sampling strategy. Notably some cruises with coarse spatial resolution required a different procedure for the crossover analysis (compared to hydrographic section data, see Sect. 3). Among these are the four historical cruises (GEOSECS and the INDIGO cruises), three Japanese cruises conducted between Australia and Antarctica (49ZS19921203, 49HH19941213 and 49HH20011208), as well as the nine OISO cruises (Table 2) whose sampling strategy approaches that of "time-series" with summer and winter measurements collected at a few stations visited regularly since 1998 (Jabaud-Jan et al., 2004; Metzl, 2009). While most of the OISO data were collected in the upper $1000 \mathrm{~m}$, at least one deep station (to the bottom) was performed during each cruise in the vicinity of previously sampled sites in order to allow data cross-checks (Fig. 1). Similarly, for the CROZEX cruise 74DI20041213, deep $\mathrm{TCO}_{2}$ and alkalinity data $(>1500 \mathrm{~m})$ were collected at two stations only, located in the vicinity of stations visited during the previous CROZEX cruise (74DI20041103) and 
Table 2. Number of stations (Nst), number of crossovers ( $\mathrm{Nx}$ ) and final adjustments applied to the CARINA data product and recommended for GLODAP cruises.

\begin{tabular}{|c|c|c|c|c|c|c|c|c|c|c|}
\hline Cruise expocode & $\begin{array}{l}\text { Common name } \\
\text { (WOCE line) }\end{array}$ & Nst & $\mathrm{Nx}$ & $\begin{array}{c}\text { Salinity } \\
{[+]}\end{array}$ & $\begin{array}{c}\mathrm{TCO}_{2} \\
{[+]}\end{array}$ & $\begin{array}{c}\text { Alkalinity } \\
{[+]}\end{array}$ & $\begin{array}{l}\text { Nitrate } \\
{[\mathrm{x}]}\end{array}$ & $\begin{array}{c}\text { Phosphate } \\
{[\mathrm{x}]}\end{array}$ & $\begin{array}{l}\text { Silicate } \\
{[\mathrm{x}]}\end{array}$ & $\begin{array}{c}\text { Oxygen } \\
{[\mathrm{x}]}\end{array}$ \\
\hline 09AR19960822 & (P12) & 67 & 9 & 0 & 0 & 0 & 1 & 1 & 1 & 0.96 \\
\hline 09AR20011029 & (SR3_2001) & 134 & 9 & 0 & 0 & 0 & 1 & 1.03 & 0.98 & 0.98 \\
\hline 35MF19980121 & OISO1 & 16 & 7 & 0 & 0 & 0 & $\mathrm{NC}$ & NA & $\mathrm{NC}$ & 1 \\
\hline 35MF19980818 & $\mathrm{OISO} 2$ & 14 & 6 & 0 & -4 & -9.0 & 1 & NA & 1.04 & 1 \\
\hline 35MF19981205 & OISO3 & 17 & 13 & 0 & 0 & 0 & 1 & NA & 1.04 & 0.99 \\
\hline 35MF19990104 & ANTARES4 & 35 & 1 & 0 & +43 & 0 & 1 & NA & 1 & 1 \\
\hline $35 \mathrm{MF} 20000117$ & OISO4 & 19 & 13 & 0 & 0 & NA & 0.97 & NA & 1 & 1.06 \\
\hline $35 \mathrm{MF} 20000719$ & OISO5 & 12 & 13 & 0 & 0 & 0 & 1.06 & NA & 0.96 & 1 \\
\hline $35 \mathrm{MF} 20010103$ & OISO6 & 11 & 13 & -0.010 & 0 & 0 & 1 & NA & 0.98 & 1 \\
\hline $35 \mathrm{MF} 20020104$ & OISO8 & 13 & 13 & 0 & +6.5 & 0 & $\mathrm{NC}$ & NA & 1.04 & 1 \\
\hline $35 \mathrm{MF} 20030123$ & OISO10 & 10 & 8 & -0.011 & 0 & 0 & 1 & 1.10 & 1.14 & 1 \\
\hline $35 \mathrm{MF} 20040103$ & OISO11 & 15 & 10 & -0.022 & 0 & 0 & 1 & NA & 0.95 & 1.01 \\
\hline 49HН19941213 & KH94_4 & 11 & 8 & 0 & 0 & -16.1 & 0.96 & 0.93 & 1.03 & 1 \\
\hline 49HН20011208 & KH01_3 & 18 & 8 & 0 & $\mathrm{NC}$ & NA & 1.04 & 1.04 & 1.03 & 1.04 \\
\hline $49 \mathrm{NZ20031209^{ \textrm {a } }}$ & BEAGLE leg5 & 145 & 3 & 0 & 0 & +10 & 1 & 1 & 1 & 1 \\
\hline 49ZS19921203 & JARE34 & 22 & 8 & 0 & NA & NA & 1 & 1.05 & 0.97 & 0.98 \\
\hline $61 \mathrm{TG} 20020206$ & JARE43 & 8 & 8 & 0 & 0 & NA & 0.98 & 1.05 & 1.05 & 0.97 \\
\hline $61 \mathrm{TG} 20030217$ & JARE44 & 11 & 8 & +0.005 & NA & NA & 1 & NA & 1 & 1 \\
\hline 74AB20020301 & CD139 (I5) & 146 & 4 & 0 & -4 & 0 & 0.98 & 1 & 0.98 & 1 \\
\hline 74DI20041103 & CROZEX & 46 & 5 & 0 & -4 & 0 & 1 & 0.97 & 0.90 & 1 \\
\hline 74DI20041213 & CROZEX & 59 & 6 & 0 & -4 & 0 & 1 & 1 & 0.94 & 1 \\
\hline 06AQ19960317ª & (S4A/A12) & 100 & 3 & 0 & -4 & NA & 1.02 & 1 & 1.05 & 1.01 \\
\hline $35 \mathrm{MF} 19960220^{\mathrm{a}}$ & CIVA2 (I6b) & 88 & 6 & 0 & 0 & 0 & 0.96 & 0.97 & 0.90 & 1 \\
\hline $317519950922^{\mathrm{a}}$ & (IR4) & 100 & 5 & 0 & 0 & 0 & 1 & 1 & 1 & 1 \\
\hline 09FA19941112 & (S5) & 68 & 0 & $\mathrm{NC}$ & $\mathrm{NC}$ & $\mathrm{NC}$ & $\mathrm{NC}$ & $\mathrm{NC}$ & $\mathrm{NC}$ & $\mathrm{NC}$ \\
\hline 74DI19930206 & (I8A/S4) & 25 & 8 & 0 & NA & NA & 1 & 1 & 1 & 0.96 \\
\hline 74DI19950106 & (ISS1i) & 103 & 6 & 0 & NA & NA & 1.03 & 0.98 & 1.11 & 1 \\
\hline 74DI19940219 & (ISS1h) & 32 & 6 & 0 & NA & NA & 1 & 1.02 & 1.02 & 1.01 \\
\hline $320619960503^{\mathrm{a}}$ & $(\mathrm{S} 4 \mathrm{I})$ & 108 & 7 & 0 & 0 & 0 & 1 & 1 & 1 & 1 \\
\hline $35 \mathrm{MF} 19930123^{\mathrm{a}}$ & CIVA1 (I6) & 52 & 4 & 0 & 0 & 0 & 0.98 & 0.98 & 0.98 & 1 \\
\hline $316 \mathrm{~N} 19941201^{\mathrm{a}}$ & $(\mathrm{I} 8 \mathrm{~S} / \mathrm{I} 9 \mathrm{~S})$ & 143 & 7 & 0 & 0 & 0 & 1 & 1 & 1 & 1 \\
\hline 09AR19941213 & (SR3/S4) & 106 & 13 & 0 & 0 & 0 & 1 & 1 & 1.03 & 1 \\
\hline 09AR19930404 & $(\mathrm{P} 11 \mathrm{~A})$ & 62 & 5 & -0.010 & 0 & NA & 1 & 0.98 & 1.07 & 1.03 \\
\hline 09FA19930624 & (P11S) & 74 & 3 & 0 & NA & NA & 0.92 & 0.95 & 0.98 & 0.99 \\
\hline 09AR19910925 & (SR3) & 26 & 8 & 0 & NA & NA & 1 & 0.93 & 1 & 1.02 \\
\hline INDIGO (1985) & INDIGO1 & 25 & 12 & 0 & -10.3 & -16 & 1 & 0.98 & 1 & 1 \\
\hline INDIGO (1986) & INDIGO2 & 49 & 1 & 0 & 0 & +7 & $\mathrm{NC}$ & $\mathrm{NC}$ & $\mathrm{NC}$ & $\mathrm{NC}$ \\
\hline INDIGO (1987) & INDIGO3 & 43 & 15 & 0 & -5.5 & 0 & 1.02 & 0.97 & 0.95 & 1 \\
\hline GEOSECS_IND & GEOSECS (st.403-454) & 51 & 5 & 0 & -23 & 0 & 1 & 1 & 1 & 1 \\
\hline
\end{tabular}

Adjustments are additive for salinity, $\mathrm{TCO}_{2}(\mu \mathrm{mol} / \mathrm{kg})$ and alkalinity $(\mu \mathrm{mol} / \mathrm{kg})$ and multiplicative for nitrate, phosphate, silicate and oxygen.

NA stands for Not Available and NC stands for Not Considered.

${ }^{a}$ Identified as core-cruise for the final inversion (see Sect. 3.3).

historical cruises. Finally, for the trans-Indian Ocean cruise $74 \mathrm{AB} 20020301$, measurements of $\mathrm{TCO}_{2}$ were performed at four stations (crossovers with WOCE lines). These measurements were used to check that $\mathrm{TCO}_{2}$ calculated from alkalinity and $\mathrm{pH}$ is consistent with GLODAP data.

Some of the cruises evaluated in this study are shared with the Atlantic and Pacific sectors of the Southern Ocean (as identified in Table 1). For those cruises the results obtained in the Indian sector are presented in Sect. 4 and com- pared to those obtained in the Atlantic and Pacific sectors by Hoppema et al. (2009) and Sabine et al. (2009), respectively. Discussions among the Southern Ocean Carbon Synthesis (SOCS) group during the final meeting in Paris led to the final adjustments reported in Table 2 that take into account the results obtained in all three sectors. 


\section{Quality control procedure and methods}

A common quality control procedure was developed for all CARINA regions. It can be divided into three successive steps: i) crossover analyses comparing deep measurements collected at nearby stations during two different cruises in order to detect any systematic offset, ii) evaluation of the cruise to cruise differences (offsets), parameter by parameter, in order to identify the cruises that could require an adjustment, and iii) adjustments are applied and crossover analyses of deep measurements are performed again to check the internal consistency of the dataset after correction. Details about the common methodology can be found elsewhere (Tanhua et al., 2009). In this section a brief description of the methods is given for the purpose of highlighting any divergence from the common procedure.

\subsection{Initial crossover analyses}

Crossover analyses are objective comparisons of deep water data $(>1500 \mathrm{~m})$ collected in the same area during two different cruises. The station distribution was such that the definition of the crossover area was variable and defined subjectively on a case by case basis: the area considered by default was a circle with a $222 \mathrm{~km}$ radius around a sampling station, but it could be decreased in frontal regions or increased in homogeneous deep waters. In cases when the crossover area covered different hydrological regions (e.g. repeated cruise lines), the crossover was separated into two or more clusters. The mean offset between data from two cruises is estimated by comparing the mean profiles generated for each cruise by averaging deep measurements found in a crossover area (or cluster) along isopycnal surfaces, as described by Tanhua et al. (2009). Crossover plots and statistics were first generated manually in order to allow the operator to change the settings when appropriate. Then, similar analyses were performed using an automated (objective) method (see Tanhua et al., 2009) but, because this method requires at least three stations per cruise to produce statistics, not all crossovers could be evaluated in this way. Most, but not all, crossovers were evaluated using the manual routine (due to time limitations and the addition of more cruise data after the initial manual checks). However, the results of the manual and automatic routines were generally in good agreement (see for example Fig. 3 in Tanhua et al., 2009). All the manually and automatically generated crossover plots can be found on the CARINA website (http://cdiac.ornl.gov/oceans/CARINA/CARINA_QC.html).

The 39 cruises in the South Indian Ocean and corresponding Antarctic sector (Table 1) generate a total of 133 crossovers. These include 57 crossovers comparing CARINA data with GLODAP data, 48 CARINA-CARINA crossovers and 28 GLODAP-GLODAP crossovers. All the crossovers that involve at least one of the CARINA cruises were evaluated manually, as well as most of those involv-
Table 3. Minimum adjustment applied to the data product and the maximum allowed adjustment in the Weighted Damped Least Square (WDLSQ) inversions for core cruises identified in Table 2 and non-core cruises.

\begin{tabular}{lccc}
\hline & Minimum & \multicolumn{2}{c}{ Maximum allowed adjustment } \\
& adjustment & Core cruises & Non-core cruises \\
\hline Salinity & 0.005 & 0.030 & 0.030 \\
$\mathrm{TCO}_{2}(\mu \mathrm{mol} / \mathrm{kg})$ & 4 & 4 & 15 \\
$\mathrm{Alkalinity}(\mu \mathrm{mol} / \mathrm{kg})$ & 6 & $6-10$ & 20 \\
Nitrate $(\%)$ & 2 & $2-10$ & 20 \\
Phosphate $(\%)$ & 2 & $2-10$ & 20 \\
Silicate $(\%)$ & 2 & $2-10$ & 20 \\
Oxygen $(\%)$ & 1 & $1-5$ & 10 \\
\hline
\end{tabular}

ing two GLODAP cruises. All the crossovers that include at least three stations per cruise were also evaluated using the automatic routine, but because the Southern Indian Ocean dataset includes a large number of cruises with coarse spatial resolution (16 cruises out of 39), many crossovers could not be evaluated this way. Among these are the nine OISO cruises (Table 1) which were totally excluded from the automatic analysis. For the other cruises with relatively coarse spatial resolution, at least one crossover area was found to satisfy the minimum of three stations required for running the automatic routine. For crossovers that include only one or two stations the plots and statistics were generated manually in a way different from the automatic method in the sense that the statistics are not comparable: for crossovers with at least three stations per cruise the error associated with the mean offset reflects the standard deviation around each cruise's mean profile (Tanhua et al., 2009), whereas for crossovers with only one or two stations per cruise the error is given by the standard deviation of the mean difference between the two profiles.

\subsection{Inversion and regional analysis}

The information deduced from the crossover analyses can be synthesized by using an inverse method in order to determine the adjustments required for maximizing the internal consistency of the dataset (Johnson et al., 2001; Tanhua et al., 2009). Results from the automatically generated crossovers were used to perform a global Southern Ocean inversion, also including the Atlantic and Pacific sectors (Hoppema et al., 2009; Sabine et al., 2009). Weighted Least Squares (WLSQ) and Weighted Dampened Least Squares (WDLSQ) methods were used for the inversions (Tanhua et al., 2009). The first method uses the standard deviation associated with each crossover and the time difference between the cruises to weight the inversion, but no a priori assumption is made on the quality of the data. In the second method a maximum allowed range of adjustments is set for each parameter and each cruise (Table 3), which tends to decrease the 
adjustments of individual cruises on cost of the overall performance of the model (Johnson et al., 2001). For the Southern Ocean, a first inversion was performed using both methods and no core-cruise for the WDLSQ inversion. The corrections proposed by these two inversions were evaluated and compared with those deduced from manually generated crossovers. This comparison shows a better agreement with results from the WDLSQ inversion than with the less complex WLSQ method. Consequently, only the results from the WDLSQ inversion are presented and discussed in the following sections.

The advantage of using an inversion to identify the cruises that could require an adjustment is that the whole Southern Ocean dataset was treated as one. A major problem is that, because the inversion is carried out using the crossover offsets generated automatically, it does not include crossovers with less than three stations per cruise and consequently the nine OISO cruises are not evaluated by the inversion. In order to evaluate these nine cruises a different method had to be used based on the manually generated crossovers. This alternative method, referred to as "regional analysis", consists in identifying a set of reliable cruises for a given parameter and to use those cruises as a reference to deduce any adjustment that could be required for the other cruises. It should be noted that another alternative would have been to include those particular cruises in the inversion by using the information obtained from the manually generated crossovers, but we decided otherwise, because the statistics that are used to weight the inversion are not comparable (Sect. 3.1). In addition it is valuable that the regional analysis and the Southern Ocean inversion remain two independent results, the first being a "manual" analysis based on crossover offsets generated manually, while the second is a fully automated procedure.

Adjustments were determined by comparing the corrections deduced from the regional analysis with the results of the WDLSQ inversion when possible. Parameters were evaluated cruise by cruise, and only corrections above a defined threshold were considered (Table 3). When the regional analysis and inversion agreed by suggesting a correction (no correction), an adjustment (no adjustment) was applied. Otherwise crossover results were carefully examined in order to collect evidence that might support one or the other suggestion. In a few cases we made no recommendation (NC in Table 2) and the data were not corrected, either because the evidence for an adjustment was poor (only one or two crossovers), or because the proposed correction was suspected to be biased (in regions where large horizontal gradients are observed at depth).

\subsection{Final check}

The last step consists in evaluating the improvement in data coherence after the adjustments were applied. This was done by performing new crossover analyses of deep data (after data adjustment) using the automatic routine (Tanhua et al., 2009) and a final Southern Ocean inversion (WDLSQ method, with core-cruises identified in Table 2). The results were evaluated in order to detect any remaining offset in the CARINA-GLODAP merged dataset. In most cases the offsets that were detected after data adjustment had already been detected with the initial inversion but no adjustment was applied to the data based on the evidence presented in Sect. 4. In such cases the crossovers generated before and after data adjustment were carefully examined and the evidence for or against an adjustment was re-evaluated. Cruise data that were adjusted before this stage of the analysis are listed in Sect. 4. In a few cases the initial recommendation was revised, so adjustments were only considered final after this last check (Table 2).

\section{Adjustments}

The final adjustments applied to CARINA data in the Indian sector of the Southern Ocean and those recommended for GLODAP data for improving the internal consistency of the CARINA-GLODAP merged dataset are reported in Table 2. These adjustments result from a critical analysis of the corrections proposed by the WDLSQ inversion based on automatically generated crossovers and/or those deduced from the regional analysis based on manually generated crossovers. The results of the initial crossover analysis (uncorrected data) are presented in Fig. 3 and compared to those proposed by the final inversion (after data correction), as well as those applied in GLODAP (Key et al., 2004). The decision for or against an adjustment is detailed on the CARINA website for all the cruises and parameters listed in Table 2 (http://cdiac.ornl.gov/oceans/CARINA/CARINA_QC. html) (Tanhua et al., 2009). Here, the main results of the initial crossover analysis and the final inversion are summarized parameter by parameter, with more emphasis on cruises identified for correction. Each section is organized as follows. The initial crossover analysis is presented first. The corrections proposed by the initial inversion are discussed and compared to those deduced from the regional analysis and a decision is made based on the best available evidence. For the cruises not evaluated in the inversion, the results of the regional analysis are presented in more detail. Finally, the results of the final inversion are presented and discussed (when CARINA and GLODAP cruise data are adjusted following the initial recommendations).

A few general considerations should be discussed first, as they are relevant for most (if not all) parameters. Despite the coarse spatial resolution of the nine OISO cruises, good confidence is given to the regional analysis because it is based on a double check: the internal consistency of the OISO dataset was first checked, then the data were compared to other measurements collected in the vicinity of the deep OISO stations (Fig. 1, essentially INDIGO data). A good agreement was generally obtained. For the six other cruises with 
a)

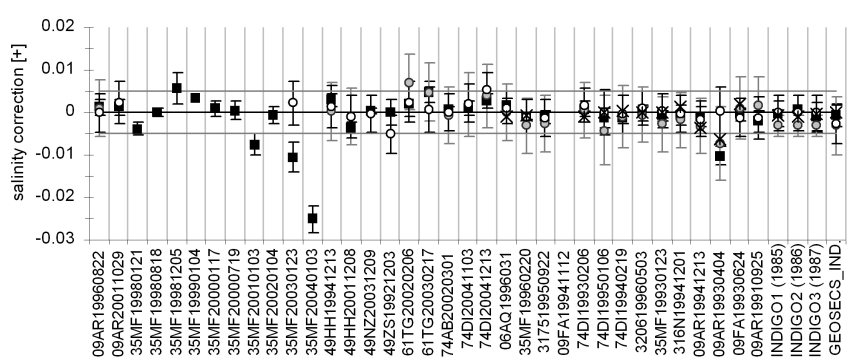

b)

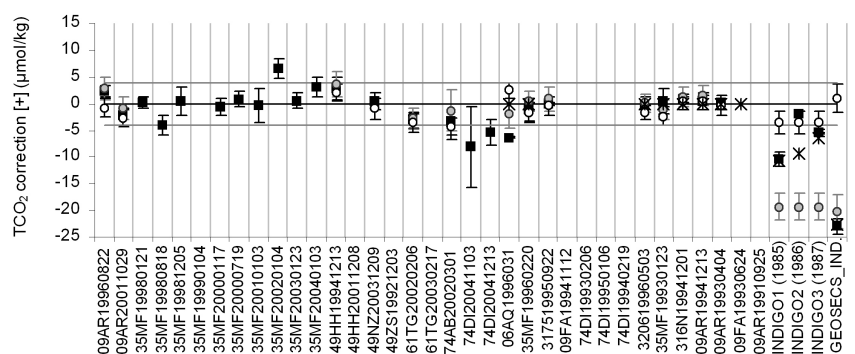

e)

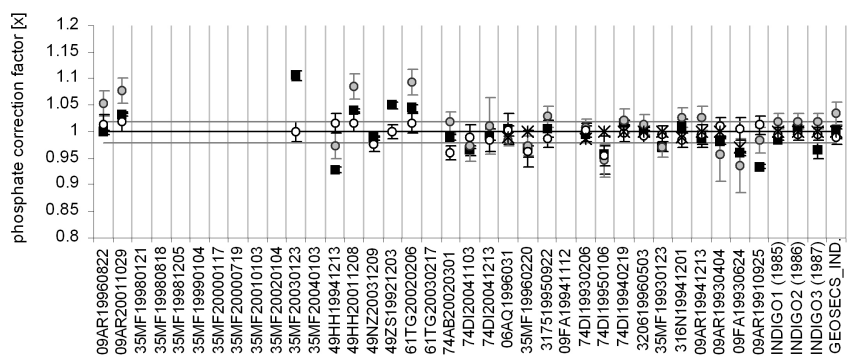

c)

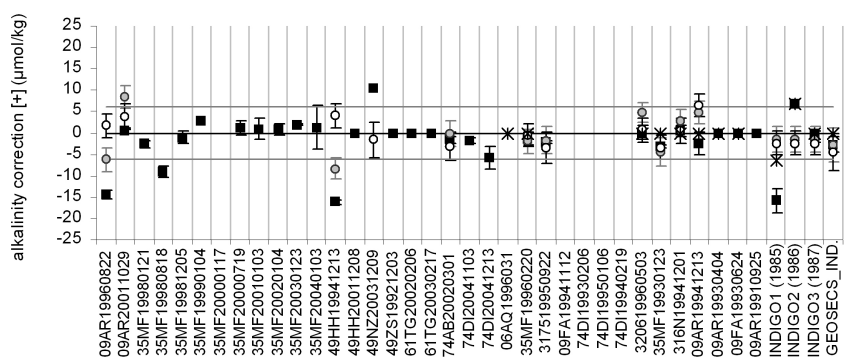

f)

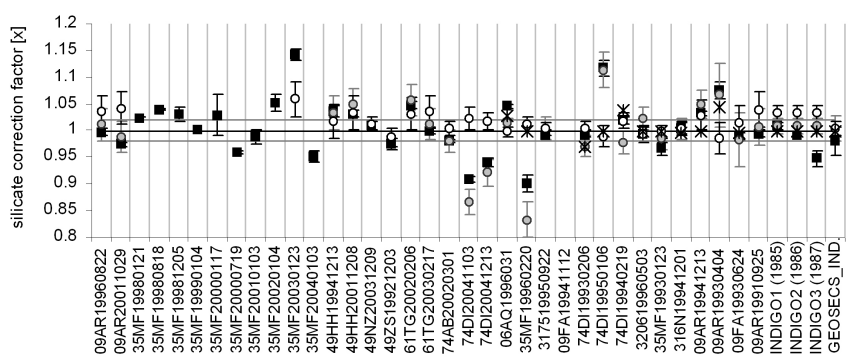

g)
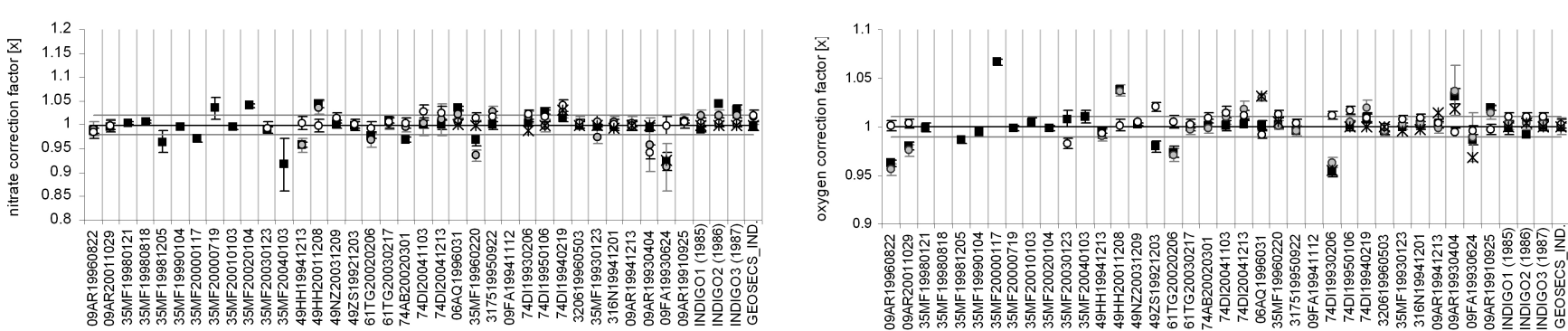

Figure 3. Corrections (additive) and correction factors (multiplicative) obtained from different methods for (a) salinity (b) $\mathrm{TCO}_{2}$, (c) alkalinity, (d) nitrate, (e) phosphate, (f) silicate and (g) oxygen. Results obtained with the WDLSQ inversion before and after data correction (gray and white dots, respectively) and from the regional analysis (black squares) are compared with previous estimates (GLODAP corrections, black crosses). Only adjustments above a defined threshold were considered for correction (salinity: $0.005, \mathrm{TCO}_{2}: 4 \mu \mathrm{mol} / \mathrm{kg}$, alkalinity: $6 \mu \mathrm{mol} / \mathrm{kg}$, nutrients: $2 \%$ and oxygen: $1 \%)$.

relatively coarse spatial resolution (GEOSECS, INDIGO, 49ZS19921203, 49HH19941213 and 49HH20011208), at least one crossover area was found to satisfy the minimum of three stations allowing one or more automatic crossovers for each cruise. For some of the cruises this information was suf- ficient to be evaluated by the inversion, but low confidence is given to the results because they are based on few crossovers. Another problem with the results of the inversion is that the three INDIGO cruises conducted in 1985 (INDIGO1), 1986 (INDIGO2) and 1987 (INDIGO3) are considered as 
one single cruise. This would have no consequence if the three INDIGO data sets had no (or a similar) offset. A previous study suggested different offsets for $\mathrm{TCO}_{2}$ and alkalinity (Sabine et al., 1999), and it is likely that the inversion failed at least for these two parameters. In addition, the corrections deduced from the regional analysis for the cruise INDIGO2 should also be considered with care because only one crossover was found for this cruise (Table 2). The same holds for the results for cruise 35MF19990104 (ANTARES4), results were obtained by increasing the size of the crossover area in order to include stations sampled during INDIGO1 (located about $5^{\circ}$ to the west of the ANTARES4 site). For 09FA19941112, no crossover was found with any of the other cruises assembled in the dataset. No recommendation is made for this cruise in Table 2.

\subsection{Salinity}

\subsubsection{Initial crossover analysis - salinity}

Salinity was measured during all the cruises in the CARINAGLODAP merged dataset. Since international standards are used for salinity measurements, one can expect to find very few offsets. A total of 133 crossovers were generated with salinity data for the cruises listed in Table 2. Most of them were generated both manually (127 crossovers) and using the automatic (common) routine (85 crossovers). The corrections deduced from the regional analysis (based on manually generated crossovers) and the WDLSQ inversion (based on automatically generated crossovers) are compared in Fig. 3a. A good agreement is obtained for most of the cruises. When a small disagreement exists, the inversion generally suggests a larger correction than the one deduced from the regional analysis. Most of the GLODAP cruises have already been checked for offsets in salinity (Gouretski and Jancke, 2001; Johnson et al., 2001). The corrections (no correction) applied in GLODAP (Key et al., 2004) are in very good agreement with those deduced from the present analysis (Fig. 3a).

The automatic routine generated 85 crossovers and only 15 of them show a significant offset in salinity $(>0.005)$. The inversion identified only three cruises that should be considered for correction: 61TG20020206, 61TG20030217 and the GLODAP cruise 09AR19930404. The result of the inversion for cruise 61TG20020206 is surprising, as it is based on eight crossovers that show no systematic offsets compared to cruises that are thought to have good salinity data. This suggests that no correction would be required, in good agreement with the conclusion of the regional analysis. Consequently no adjustment is applied to salinity measurements for this cruise (Table 2). For the other cruises, 61TG20030217 and 09AR19930404, an adjustment is applied based on the good agreement between the inversion and the regional analysis (and the GLODAP correction for cruise 09AR19930404).
More crossovers were generated manually and again relatively few offsets were detected (35 crossovers out of 126), which makes it easy to identify the cruises that could require an adjustment. In addition to those already mentioned, four OISO cruises not evaluated in the inversion were identified for salinity correction (35MF19981205, 35MF20010103, 35MF20030123 and 35MF20040103, Fig. 3a). For each OISO cruise between 8 and 13 crossovers found north and south of the Polar Front were analyzed. For the nine OISO cruises evaluated in this study salinity data recorded by the CTD (Conductivity-Temperature-Depth) sonde was used rather than bottle salinity, because measurements were not performed at all sampling depths. However, the few measurements that were performed at each station were used to check and eventually to correct the continuous salinity profile derived from the CTD sensor. Consequently similar offsets would be detected using either CTD or bottle salinity (i.e., any adjustment detected for CTD data also applies to salinity measurements). For the cruises 35MF20030123 and 35MF20040103, all crossovers show systematic and coherent offsets, leading to the adjustments reported in Table 2. For the two other OISO cruises mentioned above (35MF19981205 and 35MF20010103) it is likely that ocean interior variability also played a role, which would explain that different offsets are detected north and south of the Polar Front. Higher confidence is given to the station in the subtropical region $\left(30^{\circ} \mathrm{S}\right)$ than the one located at $56^{\circ} \mathrm{S}$ because deep data are generally more noisy south of the Polar Front, probably due to larger horizontal gradients in deep waters. Therefore, no adjustment is applied to salinity for these two cruises (35MF19981205 and 35MF20010103) despite the offset detected at $56^{\circ} \mathrm{S}$ in December 1998.

\subsubsection{Final inversion - salinity}

Based on the initial crossover analysis, salinity data from five cruises were adjusted prior to the final analysis: 35MF20010103 (-0.010), 35MF20030123 (-0.011), 35MF20040103 (-0.022), 61TG20030217 (-0.005) and 09AR19930404 (-0.011). Only small corrections are proposed by the final inversion, either below or close to the limit of 0.005 (Fig. 3a). The largest corrections are proposed for cruises 49ZS19921203 and 74DI20041213, while for all other cruises the proposed correction is below 0.003 . Low confidence is given to the result of the inversion for cruise 49ZS19921203, because it is based on one crossover only, whereas the regional analysis is based on the analysis of eight crossovers that show no significant offset in salinity for this cruise. For cruise 74DI20041213 the regional analysis is based on six reliable crossovers that indicate an average correction of $+0.003 \pm 0.002$, which is in good agreement with the result of the two inversions $(+0.004 \pm 0.008$ initially and $+0.005 \pm 0.004$ after data correction). This suggests that salinity data for cruise 74DI20041213 might be 
slightly low, but the correction is too small to justify an adjustment (Table 2).

\section{$4.2 \mathrm{TCO}_{2}$}

\subsubsection{Initial crossover analysis $-\mathrm{TCO}_{2}$}

$\mathrm{TCO}_{2}$ was measured during 32 cruises out of 39 (Table 2), resulting in a total of 80 crossovers. The historical cruises (GEOSECS and INDIGO) were conducted before the use of Certified Reference Material (CRM, introduced by A. G. Dickson, Scripps Institution of Oceanography, in 1991). In addition, the crossovers south of the Polar Front $\left(\sim 50^{\circ} \mathrm{S}\right)$ must be considered with care, because a small increase in $\mathrm{TCO}_{2}$ can be expected in Antarctic deep waters due to anthropogenic $\mathrm{CO}_{2}$ that has penetrated deeply in the Southern Ocean (Lo Monaco et al., 2005a, b; Vazquez et al., 2009). For all other cruises, one can expect to detect only small offsets. And indeed near-zero corrections are deduced from the inversion and the regional analysis for most of the cruises (Fig. 3b). Still, seven of them could require an adjustment, as discussed below. Figure $3 \mathrm{~b}$ also shows a very good agreement between the results of the inversion and the regional analysis, as well as with the corrections (no correction) proposed in previous studies (GLODAP corrections taken from Sabine et al. (1999), Lamb et al. (2003) and Wanninkhof et al. (2003)).

Only half of the 80 crossovers were generated automatically and used in the inversion (41 crossovers). Despite the relatively large number of crossovers showing a significant offset in $\mathrm{TCO}_{2}(20$ crossovers $>4 \mu \mathrm{mol} / \mathrm{kg}$ ), the inversion identified only four cruises that should be considered for correction: the three INDIGO cruises and GEOSECS. An adjustment of $-23 \mu \mathrm{mol} / \mathrm{kg}$ is applied to GEOSECS data in the view of the close agreement found between the inversion, the regional analysis and the adjustment applied in GLODAP $(-22.5 \mu \mathrm{mol} / \mathrm{kg})$. The inversion suggests that the INDIGO cruises may require an adjustment, but the correction proposed by the inversion is disregarded because INDIGO was evaluated as one single cruise. Instead, the adjustments reported in Table 2 result from the regional analysis that evaluated the three cruises individually. The adjustments applied to $\mathrm{TCO}_{2}$ data from INDIGO1 $(-10.3 \mu \mathrm{mol} / \mathrm{kg})$ and INDIGO3 $(-5.5 \mu \mathrm{mol} / \mathrm{kg})$ are in good agreement with those applied in GLODAP $(-10.7 \mu \mathrm{mol} / \mathrm{kg}$ and $-6.4 \mu \mathrm{mol} / \mathrm{kg}$, respectively). No adjustment is applied to $\mathrm{TCO}_{2}$ data from INDIGO2 based on the comparison with data from the BEAGLE cruise (49NZ20031209) and with INDIGO1 data. This result contradicts the adjustment applied in GLODAP $(-9.4 \mu \mathrm{mol} / \mathrm{kg})$. The inversion and the regional analysis also disagree for two other cruises, the GLODAP cruise 06AQ19960317 and the CARINA cruise 74AB20020301. For the cruise 06AQ19960317, no correction is proposed by the inversion, in agreement with GLODAP. However, the careful analysis of crossovers found in the Indian sector (this study) and the Atlantic sector (Hoppema et al., 2009) suggests that a small correction would be required $(-6 \mu \mathrm{mol} / \mathrm{kg}$ and $-4 \mu \mathrm{mol} / \mathrm{kg}$, respectively). The lowest correction deduced from data in the Atlantic sector is preferred, because only three crossovers are found in the Indian sector and all three are located near $50^{\circ} \mathrm{S}$ at the Indian-Atlantic boundary, a region subject to large interannual variability. For cruise 74AB20020301, the regional analysis suggests a small correction of $-3.3 \mu \mathrm{mol} / \mathrm{kg}$, below the limit of $4 \mu \mathrm{mol} / \mathrm{kg}$. Since the inversion suggested no correction, no adjustment was applied at first. This result was modified after the final inversion which suggests a correction of $-4.4( \pm 1.6) \mu \mathrm{mol} / \mathrm{kg}$, in agreement with the PI's recommendation to decrease $\mathrm{TCO}_{2}$ by $4 \mu \mathrm{mol} / \mathrm{kg}$ (Álvarez et al. 2009).

Through the regional analysis, we identified five cruises not evaluated by the inversion, that could require an adjustment: two OISO cruises (35MF19980818 and 35MF20020104), the ANTARES4 cruise (35MF19990104) and the two CROZEX cruises (74DI20041103 and 74DI20041213). Between five and thirteen crossovers were analyzed for each OISO cruise. These show systematic offsets for two cruises with crossovers either north of the Polar Front only (35MF19980818) or north and south of the Polar Front (35MF20020104), leading to the adjustments reported in Table 2. The large offset detected for ANTARES4 $(-43 \pm 2 \mu \mathrm{mol} / \mathrm{kg})$ is surprising given that CRM was used. Nevertheless, it is supported by $\mathrm{TCO}_{2}$ calculated from alkalinity and $\mathrm{pH}$ that is higher than the measured $\mathrm{TCO}_{2}$ by 29 $( \pm 8) \mu \mathrm{mol} / \mathrm{kg}$ (B. Delille, 2009, personal communication). The CROZEX cruises 74DI20041103 and 74DI20041213 were conducted back to back (Bakker et al., 2007) and no offset was detected between these two cruise data. Three other crossovers are found for these two cruises, with three historical cruises: INDIGO1, INDIGO3 and GEOSECS, all known to have high $\mathrm{TCO}_{2}$ data (Table 2). When this is taken into account all three crossovers suggest that the CROZEX $\mathrm{TCO}_{2}$ data are higher than the corrected historical data. The correction proposed for the two CROZEX cruises range from 4 to $13 \mu \mathrm{mol} / \mathrm{kg}$, which reflects the uncertainty of the historical data. The smallest correction is applied (Table 2).

\subsubsection{Final inversion $-\mathrm{TCO}_{2}$}

Based on the initial crossover analysis, $\mathrm{TCO}_{2}$ data from eight cruises were adjusted prior to the final analysis: the CARINA cruises 35MF19980818 $(-4 \mu \mathrm{mol} / \mathrm{kg})$, $35 \mathrm{MF} 19990104 \quad(+43 \mu \mathrm{mol} / \mathrm{kg}), \quad 35 \mathrm{MF} 20020104$ $(+6.5 \mu \mathrm{mol} / \mathrm{kg}), \quad 74 \mathrm{DI} 20041103 \quad(-4 \mu \mathrm{mol} / \mathrm{kg}) \quad$ and 74DI20041213 $(-4 \mu \mathrm{mol} / \mathrm{kg})$ and the GLODAP cruises INDIGO1 $(-10.3 \mu \mathrm{mol} / \mathrm{kg})$, INDIGO3 $(-5.5 \mu \mathrm{mol} / \mathrm{kg})$ and GEOSECS $(-23 \mu \mathrm{mol} / \mathrm{kg})$. The inversion performed after data correction suggests that a significant offset could remain for one cruise: 74AB20020301 (Fig. 3b). For this cruise it was decided to revise the initial result (no adjustment) to an adjustment of $-4 \mu \mathrm{mol} / \mathrm{kg}$ based on the good agreement 
between the result of the final inversion $(-4.4 \pm 1.6 \mu \mathrm{mol} / \mathrm{kg})$ and an independent analysis performed by Álvarez et al. (2009) who concluded that calculated $\mathrm{TCO}_{2}$ data should be decreased by $4 \mu \mathrm{mol} / \mathrm{kg}$. The regional analysis also detected high $\mathrm{TCO}_{2}$ measurements for this cruise, but a smaller correction was proposed $(-3.3 \pm 3.3 \mu \mathrm{mol} / \mathrm{kg})$ whereas the initial inversion proposed no correction $(-1.3 \pm 3.9 \mu \mathrm{mol} / \mathrm{kg})$.

A correction of $-18( \pm 2) \mu \mathrm{mol} / \mathrm{kg}$, is suggested by the final inversion for cruise 35MF20030123 (result not shown in Fig. 3b), but it is disregarded because it was obtained using $\mathrm{TCO}_{2}$ data not adjusted to CRMs. When CRM adjusted $\mathrm{TCO}_{2}$ is used (data in the individual cruise file), no offset is detected. Consequently no adjustment is applied (Table 2). The inversion suggests a correction factor close to the limit of $4 \mu \mathrm{mol} / \mathrm{kg}$ for the INDIGO cruises. This result is based on four crossovers generated after data correction which show an offset of $+4 \pm 5 \mu \mathrm{mol} / \mathrm{kg}$ for cruise INDIGO2 (crossover with GEOSECS), but no significant offset for the cruises INDIGO1 and INDIGO3. The latter gives support to the adjustments recommended for these two cruises (Table 2), in agreement with the adjustments applied in GLODAP $(-10.7 \mu \mathrm{mol} / \mathrm{kg}$ and $-6.4 \mu \mathrm{mol} / \mathrm{kg}$, respectively). For INDIGO2, comparison with $\mathrm{TCO}_{2}$ data from the BEAGLE cruise led to no adjustment before the final inversion. Because good confidence is given to this result, no further change is made (Table 2), which disagrees with the GLODAP correction of $-9.4 \mu \mathrm{mol} / \mathrm{kg}$ (Sabine et al., 1999).

\subsection{Alkalinity}

\subsubsection{Initial crossover analysis - alkalinity}

Alkalinity was measured at 27 cruises out of 39 (Table 2), resulting in a total of 61 crossovers. As for $\mathrm{TCO}_{2}$, CRMs were used for alkalinity measurements during most of WOCE and post-WOCE cruises. However, CRM analyses for alkalinity were not made on early cruises (INDIGO and GEOSECS), and on CARINA cruises 49HH19941213 and 09AR19960822, whereas CRMs were used on these two cruise for $\mathrm{TCO}_{2}$ measurements. Thus, biases are likely for these cruises, as suggested in Fig. 3c for three of them (49HH19941213, INDIGO1 and INDIGO2). Figure 3c also shows that a good agreement exists between the results of the inversion and the regional analysis for about half of the cruises evaluated by the two methods. For some of the GLODAP cruises, a third independent result is available (GLODAP corrections taken from Sabine et al., 1999; Lamb et al., 2003; and Wanninkhof et al., 2003), which shows a better agreement with the results from the regional analysis compared to the inversion.

Less than half of the 61 crossovers were generated automatically and used for the inversion (26 crossovers). Only ten of them show a significant offset in alkalinity $(>5 \mu \mathrm{mol} / \mathrm{kg})$. Thus the inversion identifies three cruises that should be considered for alkalinity correction:
09AR19960822, 09AR20011029 and 49HH19941213. For all three cruises the corrections proposed by the inversion and those deduced from the regional analysis differ by about $8 \mu \mathrm{mol} / \mathrm{kg}$. Good evidence supports the results from the regional analysis, including the recommendation by the data PIs. Consequently, no adjustment is applied for cruise 09AR20011029, while alkalinity is decreased by $13.7 \mu \mathrm{mol} / \mathrm{kg}$ for cruise 09AR19960822 and by $16.1 \mu \mathrm{mol} / \mathrm{kg}$ for cruise 49HH19941213 (Table 2). Importantly, $\mathrm{TCO}_{2}$ and alkalinity data from cruise 09AR19960822 were updated after the crossover analysis (data corrected for a titration cell volume error), and the final data show no offset compared to data from cruise 09AR20011029. Consequently, preliminary data were adjusted prior to the final inversion, but no adjustment is applied to the final data in the data product (Table 2).

The inversion suggests no correction for the historical cruises (GEOSECS and INDIGO). For GEOSECS this is in good agreement with the regional analysis and GLODAP corrections (Sabine et al., 1999). Therefore no adjustment is applied to GEOCSECS alkalinity data. The adjustments applied to INDIGO data are based on the regional analysis. For INDIGO1, a larger adjustment is applied here $(-16 \mu \mathrm{mol} / \mathrm{kg})$ than in GLODAP $(-6.5 \mu \mathrm{mol} / \mathrm{kg}$, Sabine et al., 1999). Good confidence is given to the larger adjustment, as more crossovers are now available, including six crossovers with CARINA cruises thought to have good alkalinity data and that show offsets ranging from 14 to $20 \mu \mathrm{mol} / \mathrm{kg}$. For INDIGO2, only one crossover was found, suggesting a correction of $+7 \mu \mathrm{mol} / \mathrm{kg}$, which supports the adjustment applied in GLODAP $(+6.8 \mu \mathrm{mol} / \mathrm{kg}$, Sabine et al., 1999). For INDIGO3, crossovers found north of the Polar Front suggest no correction, in good agreement with GLODAP (Sabine et al., 1999). However, the seven crossovers south of the Polar Front show offsets increasing with time: from about $-6 \mu \mathrm{mol} / \mathrm{kg}$ over a 9 years-period (with cruise 320619960503 ) to $-17 \mu \mathrm{mol} / \mathrm{kg}$ over a 17 years-period (with cruise 35MF20040103). This signal is attributed to ocean variability in the complex polar frontal region and consequently no adjustment is applied to INDIGO3 alkalinity data.

Two other cruises not evaluated in the inversion were identified for alkalinity correction by the regional analysis: the OISO2 cruise (35MF19980818) and the BEAGLE cruise (Leg 5: 49NZ20031209). As for INDIGO3, the offset detected at $56^{\circ} \mathrm{S}$ for $\mathrm{OISO} 2$ is disregarded and instead, an adjustment of $-9 \mu \mathrm{mol} / \mathrm{kg}$ is applied based on crossovers found north of the Polar Front (Table 2). For the BEAGLE cruise, the correction proposed $(+10 \mu \mathrm{mol} / \mathrm{kg})$ agrees with a previous analysis conducted by the data PIs who concluded that alkalinity measured along the Indian line (Leg 5) are systematically lower by 5 to $10 \mu \mathrm{mol} / \mathrm{kg}$ compared to WOCE data (Uchida and Fukasawa, 2005). 


\subsubsection{Final inversion - alkalinity}

Based on the initial crossover analysis, alkalinity data from six cruises were adjusted prior to the final analysis: preliminary data from cruise 09AR19960822 $(-13.7 \mu \mathrm{mol} / \mathrm{kg})$, the CARINA cruises 35MF19980818 $(-9 \mu \mathrm{mol} / \mathrm{kg})$, 49HH19941213 (-16.1 $\mu \mathrm{mol} / \mathrm{kg}), \quad 49 \mathrm{NZ20031209}$ $(+10 \mu \mathrm{mol} / \mathrm{kg})$ and the GLODAP cruises INDIGO1 $(-16 \mu \mathrm{mol} / \mathrm{kg})$ and INDIGO2 $(+7 \mu \mathrm{mol} / \mathrm{kg})$. The final inversion still suggests an additional adjustment for one cruise: 09AR19941213 (Fig. 3c). Since no adjustment was applied to these data, the correction suggested by the final inversion $(+6 \pm 3 \mu \mathrm{mol} / \mathrm{kg})$ is close to the result of the initial inversion $(+5 \pm 3 \mu \mathrm{mol} / \mathrm{kg})$. The regional analysis also suggested a small correction for data collected between $130^{\circ} \mathrm{E}-150^{\circ} \mathrm{E}$ $(+4 \mu \mathrm{mol} / \mathrm{kg})$, but no offset was detected for data collected between $110^{\circ} \mathrm{E}-120^{\circ} \mathrm{E}$. Consequently, no change is made to the initial result (no adjustment), because it is likely that the signal detected at $130^{\circ} \mathrm{E}-150^{\circ} \mathrm{E}$ reflects ocean variability.

Similar to $\mathrm{TCO}_{2}$, the correction of $-6( \pm 3) \mu \mathrm{mol} / \mathrm{kg}$ suggested by the final inversion for cruise 35MF20030123 (result not shown in Fig. 3c) is disregarded because it was obtained using alkalinity data not adjusted to CRMs. When CRM adjusted alkalinity is used (data in the individual cruise file), no offset is detected, and consequently, no adjustment is applied (Table 2).

\subsection{Nitrate}

\subsubsection{Initial crossover analysis - nitrate}

Nitrate was measured on all the cruises. No international reference material existed for nutrient measurements and, as a result, offsets were detected in many crossovers. A total of 131 crossovers were found and 125 of them were generated manually, half of which show significant offsets in nitrate $(>2 \%)$. Most of the cross-overs were also generated automatically and used in the inversion (84 crossovers, including 42 that show a significant offset in nitrate). The large number of significant offsets complicates the task of identifying the cruises that could require an adjustment. Nevertheless, the results of the regional analysis and the inversion are in good agreement for about two thirds of the cruises evaluated by the two methods (Fig. 3d). For most of the GLODAP cruises, a third independent result is available (Gouretski and Jancke, 2001 and L. Gordon and C. Mordy, 2003, personal communication), which shows a better agreement with results from the regional analysis than with the inversion (Fig. 3d). Additive corrections $\left(\mathrm{C}^{\text {add }}\right)$ taken from Gouretski and Jancke (2001) were converted into correction factors $\left(\mathrm{C}^{\mathrm{mul}}\right)$ following Eq. (1), with a mean concentration $(C)$ of $32 \mu \mathrm{mol} / \mathrm{kg}$.

$\mathrm{C}^{\mathrm{mul}}=1+\left(\mathrm{C}^{\mathrm{add}} / C\right)$

The inversion identifies ten cruises for nitrate correction: 49HH19941213, 49HH20011208, 61TG20020206, and the GLODAP cruises 06AQ19960317, 35MF19960220, 317519950922, 74DI19940219, 35MF19930123, 09AR19930404 and 09FA19930624. The correction factors proposed for five of them are in good agreement with those deduced from the regional analysis. The corresponding adjustments are applied to nitrate data from those cruises (49HH19941213, 49HH20011208, 61TG20020206, 06AQ19960317 and 09FA19930624). A good agreement is also found for cruise 74DI19940219, but no adjustment is applied for two reasons: i) three crossovers of this cruise with cruises that are thought to have good nitrate data (74DI20041103, 74DI20041213 and 74DI19930206) show no systematic offset and ii) the proposed correction is close to the limit of $2 \%$. Disagreement between the results from the regional analysis and the inversion exist for four cruises. For two of them, 35MF19960220 and 35MF19930123, the inversion proposes a larger correction $(0.94$ and 0.97 , respectively) than the regional analysis (0.95-0.98 and $0.98-1.00$, respectively). The scatter in the results of the regional analysis probably reflects both interannual and spatial variability, as some of the crossovers are located around $40^{\circ} \mathrm{S}$ at the Indian-Atlantic boundary, a region where deep eddies have been observed (Lo Monaco et al., 2005a), while other crossovers are located in the frontal region $\left(\sim 50^{\circ} \mathrm{S}\right)$ where large horizontal gradients exist. Nevertheless, the results of the regional analysis are in good agreement with those obtained in the Atlantic sector $(0.95$ for cruise 35MF19960220 and 0.98 for cruise 35MF19930123) (Hoppema et al., 2009). The latter adjustment is applied to nitrate data from cruise 35MF19930123 (Table 2), whereas for cruise 35MF19960220 the correction factor has been re-evaluated to 0.96 in the final check (see Sect. 4.4.2). For cruises 317519950922 and 09AR19930404 no adjustment is applied based on the analysis of nine crossovers, including six crossovers that show no offset with cruises that are thought to have good nitrate data.

Two other cruises, 74AB20020301 and 74DI19950106 have discrepancies between the crossover analyses. The inversion proposes no correction, whereas the regional analysis suggests a small correction. The result of the inversion for cruise 74DI19950106 is surprising, as it is not coherent with the analysis of the five automatically generated crossovers used in the inversion for this cruise: all crossovers show low nitrate for this cruise and two of them involve cruises that are thought to have good nitrate data (74DI20041103 and 74DI20041213). For this reason the correction factor of 1.03 deduced from the regional analysis for cruise 74DI19950106 is applied. An adjustment is also applied to nitrate data from the first cruise mentioned above (74AB20020301) based on the good agreement between the correction factor deduced from the regional analysis and an independent analysis performed by the data PI who concluded that the nitrate data should be reduced by $0.978( \pm 0.003)$.

The regional analysis also suggests that two INDIGO cruises could require a correction (Fig. 3d). For INDIGO2, 
only one crossover was analyzed and there is insufficient evidence to recommend an adjustment. Fifteen crossovers were analyzed for INDIGO3, but only those found north of the Polar Front show a coherent offset $(0.979 \pm 0.007)$, leading to the adjustment of 1.02 reported in Table 2. For the other crossovers, located at $56^{\circ} \mathrm{S}$, it is likely that ocean variability also played a role, as also suspected for salinity and alkalinity.

Finally five OISO cruises, not evaluated in the inversion, were also considered for nitrate correction: 35MF19981205, 35MF20000117, 35MF20000719, 35MF20020104 and 35MF20040103. Only crossovers found in the subtropical region show coherent offsets leading to the adjustments (no adjustment) reported in Table 2. As also observed for the INDIGO data, we found inconsistencies between crossovers at $56^{\circ} \mathrm{S}$ attributed to ocean variability. As a consequence we made no suggestion for the cruises 35MF19980121 and 35MF20020104, for which all crossovers are located at $56^{\circ} \mathrm{S}$.

\subsubsection{Final inversion - nitrate}

Based on the initial crossover analysis, nitrate data from twelve cruises were adjusted prior to the final analysis: CARINA cruises 35MF20000117 (0.97), 35MF20000719 (1.06), 49HH19941213 (0.96), 49HH20011208 (1.04), 61TG20020206 (0.98) and 74AB20020301 (0.98) and GLODAP cruises 06AQ19960317 (1.02), 35MF19960220 (0.95), 74DI19950106 (1.03), 35MF19930123 (0.98), 09FA19930624 (0.92) and INDIGO3 (1.02). The inversion performed after data correction suggests that offsets remain for six cruises: 74DI20041103, 74DI20041213, 74DI19930206, 35MF19960220, 74DI19940219 and 09AR19930404 (Fig. 3d). For one of these, cruise 35MF19960220, the final inversion suggests that the initial adjustment of 0.95 applied to the nitrate data might be too large, and proposes to correct the data by a further $1.01( \pm 0.01)$. This new result is in good agreement with the correction factor deduced from the regional analysis $(0.965 \pm 0.015)$. Thus, a final adjustment of 0.96 is recommended for nitrate data from this cruise (Table 2). For the other five cruises, no adjustment was applied after the first crossover analysis. For cruises 74DI20041103, 74DI20041213 and 74DI19930206 the final inversion proposes correction factors of $1.03( \pm 0.01), 1.03( \pm 0.01)$ and $1.02( \pm 0.01)$, respectively. This is surprising since automatically generated crossovers show no significant offset before or after data correction. For the two other cruises, 74DI19940219 and 09AR19930404, slightly larger corrections are proposed by the final inversion $(1.04 \pm 0.01$ and $0.94 \pm 0.01$, respectively) than by the first inversion $(1.03 \pm 0.01$ and $0.96 \pm 0.06$, respectively). However, about half of the automatically generated crossovers show no offset in nitrate, in good agreement with the manually generated crossovers which suggest only small offsets $(0.99 \pm 0.02$ and $1.01 \pm 1.01$, respectively).

\subsection{Phosphate \\ 4.5.1 Initial crossover analysis - phosphate}

Phosphate was measured at 29 of the 39 cruises (Table 2). The absence of international reference material for nutrient measurements was evident from the large number of offsets detected for many crossovers. A total of 82 crossovers were found among the cruises. 76 crossovers were generated manually and almost two third of them show significant offsets in phosphate (47 crossovers $>2 \%$ ). 77 crossovers were generated automatically and used in the inversion, including 50 crossovers that show a significant offset in phosphate. Corrections deduced from the regional analysis and the inversion agree for about half of the cruises evaluated by the two methods (Fig. 3e). In case of a disagreement, the value proposed by the inversion is generally higher than the one deduced from the regional analysis. For most GLODAP cruises, a third independent result is available (Gouretski and Jancke, 2001 and L. Gordon and C. Mordy, 2003, personal communication) and, as for alkalinity and nitrate, a better agreement is observed with results from the regional analysis than with the inversion (Fig. 3e). Additive corrections $\left(\mathrm{C}^{\text {add }}\right)$ taken from Gouretski and Jancke (2001) were converted into correction factors $\left(\mathrm{C}^{\mathrm{mul}}\right)$ following Eq. (1), with a mean concentration (C) of $2.2 \mu \mathrm{mol} / \mathrm{kg}$.

Significant corrections $(>2 \%)$ are proposed by the inversion for all cruises found south of Tasmania but one (cruise 09AR19910925). And for all of them the correction factors proposed by the inversion and the regional analysis disagree. Interestingly for seven of them a constant disagreement of 0.05 is found, which highlights the strong dependence that exists between those cruises in both analyses. The results from the regional analysis are preferred, because they are supported by good evidence, including recommendations for no correction made by the data PI for cruise 09AR19960822. Corresponding adjustments are applied to phosphate data from the following cruises: 09AR200011029, 49HH19941213, 49HH20011208, 61TG20020206, 09AR19930404, 09FA19930624 and 09AR19910925 (see Table 2); and no adjustment for cruises 09AR19941213 and 09AR19960822.

Seven other cruises are identified by the inversion for phosphate correction: 74DI20041103, 35MF19960220, 317519950922, 74DI19950106, 35MF19930123, 316N19941201 and GEOSECS. Because the correction factors proposed for four of them are in good agreement with those deduced from the regional analysis, the corresponding adjustments are applied (74DI20041103, 35MF19960220, 74DI19950106 and 35MF19930123). For cruises 31751995092 and 316 N19941201 it is likely that the results of the inversion are most influenced by crossovers 
south of $62^{\circ} \mathrm{S}$ that show an offset of 0.97 , whereas six crossovers in subtropical waters show no significant offsets with cruises that are believed to have good phosphate data. Because the evidence is insufficient to warrant an adjustment, and the suggested offset is relatively small, no adjustment is applied. For GEOSECS, the result of the inversion is disregarded because it is not consistent with the analysis of crossovers: two of the four crossovers used for the inversion show no significant offset (with cruises 31751995092 and 49NZ20031209), in good agreement with the analysis of manually generated crossovers (mean offset of $1.00 \pm 0.02$ ).

The regional analysis suggests a significant correction for INDIGO3 based on six crossovers (including three reliable crossovers with cruises that are thought to have good phosphate data), which indicate a mean offset of $1.033( \pm 0.013)$. A corresponding adjustment of 0.97 is applied. The correction deduced from the regional analysis for INDIGO2 data $(1.01 \pm 0.02)$ should be considered with care, because only one crossover was found for this cruise. Consequently no recommendation is made for this cruise ( $\mathrm{NC}$ in Table 2).

Two other cruises, not evaluated in the inversion, were also identified for phosphate correction in the regional analysis: 35MF20030123 and 49ZS19921203. A large and coherent offset $(0.904 \pm 0.007)$ is deduced for cruise 35MF20030123 based on the analysis of seven crossovers, including one with cruise 09AR19960822 that is thought to have good phosphate data. A corresponding adjustment of 1.10 is applied. Similarly, the adjustment applied to data from cruise 49ZS19921203 is based on the analysis of five reliable crossovers that indicate a coherent offset of $0.95( \pm 0.007)$. This result is further supported by the only automatically generated crossover showing an offset of 0.944 with cruise 320619960503 which is thought to have good phosphate data.

\subsubsection{Final inversion - phosphate}

Based on the initial crossover analysis, phosphate data from sixteen cruises were adjusted prior to the final analysis: the CARINA cruises 09AR20011029 (1.03), 35MF20030123 (1.10), 49HH19941213 (0.93), 49HH20011208 (1.04), 49ZS19921203 (1.05), 61TG20020206 (1.05) and 74DI20041103 (0.97) and the GLODAP cruises 35MF19960220 (0.98), 74DI19950106 (0.98), 74DI19940219 (1.02), 35MF19930123 (0.98), 09AR19930404 (0.98), 09FA19930624 (0.95), 09AR19910925 (0.93), INDIGO1 (0.98) and INDIGO3 (0.97). The inversion performed after data correction suggests that offsets remain for four cruises (two of which had already been adjusted as mentioned above): 74AB20020301, 49NZ20031209, 35MF19960220 (adjusted) and 74DI19950106 (adjusted) (Fig. 3e). For cruise 35MF19960220, the final inversion suggests that the adjustment of 0.98 applied to phosphate data might be too low. Because this is in good agreement with the correction factor deduced from the regional analysis $(0.97 \pm 0.03)$, an adjustment of 0.97 is recommended instead (Table 2). For the other three cruises mentioned above, no change was made to the initial results, because they are based on good evidence and it is likely that the final inversion failed since the crossovers generated after data adjustment (and used for the inversion) show no significant offset in phosphate.

\subsection{Silicate}

\subsubsection{Initial crossover analysis - silicate}

Silicate was measured during all the cruises evaluated here. In the absence of international reference material for nutrient measurements, offsets were detected in many crossovers. A total of 133 crossovers was generated manually, more than two third of which show significant offsets in silicate (94 crossovers $>2 \%$ ). Most of these crossovers were also generated automatically and used in the inversion (84 crossovers), including 59 that show a significant offset in silicate. Despite the large number of significant offsets that complicates the analysis, a good agreement is found between the results of the regional analysis and the inversion for about two third of the cruises evaluated by the two methods (Fig. 3f). Compared to the assessments made during GLODAP (Gouretski and Jancke, 2001 and L. Gordon and C. Mordy, 2003, personal communication), there is no general agreement to support either the regional analysis or the inversion (Fig. 3f). Additive corrections $\left(\mathrm{C}^{\text {add }}\right)$ taken from Gouretski and Jancke (2001) were converted into correction factors $\left(\mathrm{C}^{\mathrm{mul}}\right)$ following Eq. (1), with a mean concentration $(C)$ of $120 \mu \mathrm{mol} / \mathrm{kg}$. Particularly large disagreements are found between GLODAP corrections and CARINA recommendations for the cruises 35MF19960220 and 74DI19950106.

Ten cruises are identified by the inversion for silicate correction: 74DI20041103, 74DI20041213, 49HH19941213, 49HH20011208, 61TG20020206, 35MF19960220, 74DI19930206, 74DI19950106, 09AR19941213 and 09AR19930404. The correction factors proposed for four of them (49HH19941213, 61TG20020206, 74DI19950106 and 09AR19930404) are in good agreement with those deduced from the regional analysis. The corresponding adjustments are applied to silicate data from these four cruises. For the six other cruises, the inversion suggests larger corrections than the regional analysis. However, more confidence is given to the regional analysis, since it is based on strong evidence including the good agreement with the analysis of crossovers with cruises from the Atlantic sector for cruise 35MF19960220 (Hoppema et al., 2009) and the recommendation by the data PI for cruise 09AR19941213. Consequently, adjustments are applied to the following cruises: 74DI20041103, 74DI20041213, 49HH20011208, 35MF19960220 and 09AR19941213, while no adjustment is applied to cruise 74DI19930206. 
For four other cruises the correction factors proposed by the inversion are close to the limit of 0.98: 09AR20011029, 74AB20020301, 35MF19930123 and 09FA19930624. Corresponding adjustments are applied to these cruises based on the good agreement with the regional analysis and, for the cruise 74AB20020301, with the result of an independent analysis performed by the data PI who concluded that silicate should be reduced by 0.98 .

For two other cruises, 06AQ19960317 and INDIGO3, the inversion suggests that no correction is required, whereas significant corrections are deduced from the regional analysis (1.05 and 0.95 respectively). The latter adjustments are applied based on the good agreement with the analysis of crossovers from the Atlantic sector (Hoppema et al., 2009). For INDIGO3, only the crossovers found in the subtropical region show a consistent offset, leading to the adjustment reported in Table 2. The different offset found in crossovers at $56^{\circ} \mathrm{S}$ is attributed to ocean variability, as already suspected for salinity, alkalinity and nitrate. The correction deduced from the regional analysis for cruise INDIGO2 $(0.99 \pm 0.02)$ should be considered with care because it is based on only one crossover. Consequently no recommendation is made for this cruise (NC in Table 2).

Eight cruises not evaluated in the inversion have also been identified for silicate correction in the regional analysis: 49ZS19921203 and seven OISO cruises (35MF19980818, 35MF19981205, 35MF20000117, 35MF20000719, 35MF20020104, 35MF20030123 and 35MF20040103). Good confidence is given to the correction factor deduced from the regional analysis for cruise 49ZS19921203 based on four reliable crossovers with cruises that are thought to have good silicate data, leading to the adjustment reported in Table 2. The adjustments (no adjustment) applied to the OISO data are based on crossovers in the subtropical region only, due to noise in deep data collected at $56^{\circ} \mathrm{S}$. Consequently, no adjustment is applied to cruises 35MF20000117 (despite the significant offset detected at $56^{\circ} \mathrm{S}$ ) and 35MF19980121, for which all crossovers are at about $56^{\circ} \mathrm{S}$ (NC in Table 2).

\subsubsection{Final inversion - silicate}

Based on the initial crossover analysis, silicate data from twenty-four cruises were adjusted prior to the final analysis: 09AR20011029 (0.98), 35MF19980818 (1.04), 35MF19981205 (1.04), 35MF20000719 (0.96), 35MF20010103 (0.98), 35MF20020104 (1.04), 35MF20030123 (1.13), 35MF20040103 (0.95), 49HH19941213 (1.03), 49HH20011208 (1.04), 49ZS19921203 (0.97), 61TG20020206 (1.05), 74AB20020301 (0.98), 74DI20041103 (0.90) and 74DI20041213 (0.94) and the GLODAP cruises 06AQ19960317 (1.05), 35MF19960220 (0.90), 74DI19950106 (1.11), 74DI19940219 (1.02), 35MF19930123 (0.98), 09AR19941213 (1.04),
Table 4. Statistics for the global Southern Ocean: mean and standard deviation of the corrections proposed by the inversion (WDLSQ) before and after adjustment of the data and the number of cruises evaluated by the inversion.

\begin{tabular}{lcccccc}
\hline & \multicolumn{3}{c}{ Initial corrections } & \multicolumn{3}{c}{ Final corrections } \\
& mean & std dev & nb & mean & std dev & nb \\
\hline Salinity & 0.000 & 0.003 & 59 & 0.000 & 0.002 & 65 \\
$\mathrm{TCO}_{2}(\mu \mathrm{mol} / \mathrm{kg})$ & 0.5 & 6.5 & 35 & 0.2 & 3.5 & 45 \\
Alkalinity $\mu \mathrm{mol} / \mathrm{kg})$ & -0.9 & 5.1 & 32 & -0.1 & 4.4 & 40 \\
Nitrate & 1.000 & 0.023 & 57 & 1.001 & 0.015 & 62 \\
Phosphate & 1.002 & 0.040 & 56 & 0.999 & 0.015 & 61 \\
Silicate & 0.998 & 0.051 & 57 & 1.014 & 0.035 & 62 \\
Oxygen & 0.999 & 0.016 & 57 & 1.000 & 0.008 & 63 \\
\hline
\end{tabular}

Table 5. Statistics for the Indian sector of the Southern Ocean (same as Table 4 for cruises listed in Table 1).

\begin{tabular}{lcccccc}
\hline & \multicolumn{3}{c}{ Initial corrections } & \multicolumn{3}{c}{ Final corrections } \\
& mean & std dev & nb & mean & std dev & nb \\
\hline Salinity & -0.001 & 0.003 & 25 & 0.000 & 0.002 & 29 \\
$\mathrm{TCO}_{2}(\mu \mathrm{mol} / \mathrm{kg})$ & -4.8 & 9.0 & 16 & -1.3 & 2.1 & 18 \\
Alkalinity $(\mu \mathrm{mol} / \mathrm{kg})$ & -0.6 & 4.5 & 14 & -0.4 & 3.2 & 15 \\
Nitrate & 0.998 & 0.030 & 26 & 1.006 & 0.017 & 29 \\
Phosphate & 1.010 & 0.041 & 25 & 0.995 & 0.017 & 28 \\
Silicate & 0.999 & 0.057 & 26 & 1.017 & 0.019 & 29 \\
Oxygen & 1.001 & 0.020 & 26 & 1.005 & 0.008 & 29 \\
\hline
\end{tabular}

09AR19930404 (1.07), 09FA19930624 (0.98) and INDIGO3 (0.95). The inversion performed after data adjustment suggests that a correction could be required for the following ten cruises (most of which had already been adjusted as mentioned above): 09AR20011029 (adjusted), 35MF20030123 (adjusted), 49HH20011208 (adjusted), 61TG20020206 (adjusted), 74DI20041103 (adjusted), 09AR19941213 (adjusted), 09AR19960822, 61TG20030217, 09AR19910925 and INDIGO (Fig. 3f). Surprisingly, the final inversion proposes to increase silicate data for all of them (by a factor of 1.02 to 1.06). However, most of the crossovers generated after data adjustment and used for the inversion show no significant offset in silicate. This inconsistency probably results from a bias in the final inversion, as already suggested for the whole Southern Ocean (Table 4), also detected for the Indian sector $(1.017 \pm 0.019$, Table 5). Consequently, the final adjustments reported in Table 2 are based on a careful analysis of the crossovers generated after data adjustment, rather than the corrections proposed by the final inversion.

No change is made to the initial results for the cruises mentioned above, except for two of them: 49HH20011208 and 35MF20030123. Correction factors of $1.03 \pm 0.03$ and $1.06 \pm 0.03$, respectively, are proposed in addition to 
the adjustments already applied following the initial analysis (1.04 and 1.13, respectively). However, for cruise 49HH20011208 the analysis of crossovers generated after data adjustment reveals that the inversion is probably biased toward one single crossover with an offset of 0.97 (with cruise 49HH19941213), whereas the seven other crossovers indicate a mean offset of $1.01 \pm 0.01$. It is thus likely that the inversion failed. Nevertheless small systematic offsets remain, indicating that silicate data are now slightly high by about 1.01. This suggests that the adjustment of 1.04 could be too high and consequently an adjustment of 1.03 is applied instead, in good agreement with the regional analysis (Sect. 4.6.1), and consistent with the adjustment proposed for cruise 49HH19941213 (the manually generated crossover between the two cruises suggests that similar adjustments are required). Similarly, the result of the final inversion for cruise $35 \mathrm{MF} 20030123(1.06 \pm 0.03)$ is not coherent with the four crossovers used in the inversion which show offsets ranging from 0.96 to 0.99 . This however suggests that the adjustment of 1.13 could be too low. Consequently an adjustment of 1.14 is applied (Table 2).

The careful analysis of crossovers generated after data correction shows that systematic offsets remain for cruise 49HH19941213 (low in silicate by a factor 0.99 to 0.96 ). This suggests that the adjustment of 1.04 that was applied to these data could be too high. A final adjustment of 1.03 is applied to silicate data from this cruise (Table 2).

The result of the final inversion for INDIGO (the three cruises treated as one) is probably biased toward crossovers south of the Polar Front that indicate remaining offsets ranging from 0.96 to 0.98 , whereas those found in the subtropical region show no significant offset. This contradiction supports the idea that offsets observed in Antarctic deep waters are related to ocean variability (see Sect. 4.6.1) and consequently more confidence is given to the results obtained north of the Polar Front (no adjustment).

\subsection{Oxygen}

\subsubsection{Initial crossover analysis - oxygen}

Oxygen was measured during all the cruises. International standard exists for oxygen measurements (OSIL Iodate Standards, http://osil.co.uk), but they were not commonly used and consequently offsets were detected in many crossovers. A total of 109 crossovers was generated manually, half of which shows significant offsets in oxygen $(>1 \%)$. Most of the crossovers were also generated automatically and used in the inversion ( 83 crossovers, including 47 that show a significant offset in oxygen). Figure $3 \mathrm{~g}$ shows a good agreement between the results deduced from the regional analysis and the inversion. When the results obtained for all the cruises evaluated by the two methods are considered, an agreement within \pm 0.006 is found, but if the two cruises for which the results differ the most are removed (74DI20041213 and
06AQ19960317), the two methods agree within \pm 0.003 . For most of the GLODAP cruises, a third independent result is available (Gouretski and Jancke, 2001 and Johnson et al., 2001). Additive corrections ( $\mathrm{C}^{\text {add }}$ ) taken from Gouretski and Jancke (2001) were converted into correction factors $\left(\mathrm{C}^{\mathrm{mul}}\right)$ following Eq. (1), with a mean concentration $(C)$ of $200 \mu \mathrm{mol} / \mathrm{kg}$. In most cases good agreement is found between GLODAP corrections and CARINA recommendations.

The inversion identified ten cruises that should be considered for oxygen correction: 09AR19960822, 74DI20041213, 49HH20011208, 61TG20020206, and the GLODAP cruises 06AQ19960317, 74DI19930206, 74DI19940219, 09AR19930404, 09FA19930624, and 09AR19910925. The correction factors proposed for seven of them are in good agreement with those deduced from the regional analysis. The corresponding adjustments are applied to the oxygen data from those cruises (09AR19960822, 49HH20011208, 61TG20020206, 74DI19930206, 09AR19930404, 09FA19930624, 09AR19910925). The result of the inversion for the cruise 74DI20041213 is not coherent with the analysis of the five automatically generated crossovers used in the inversion for this cruise: only one crossover shows a significant offset in oxygen, but it involves the cruise 74DI19930206 that is thought to have high oxygen values, while the other crossovers suggest that no adjustment is required. Consequently, no adjustment is applied to this cruise. The correction factors proposed by the inversion for the GLODAP cruises 06AQ19960317 and 74DI19940219 also disagree with those deduced from the regional analysis. For cruise 06AQ19960317 a correction factor of 1.03 is proposed by the inversion, whereas the regional analysis proposed no correction. The latter, however, is based on limited evidence since the three crossovers analyzed were all located near $50^{\circ} \mathrm{S}$ at the Indian-Atlantic boundary, a region subject to large spatial variability. The analysis of this cruise in the Atlantic sector, which is based on more crossovers, suggests that a small correction could be required, leading to the adjustment reported in Table 2. A small adjustment is also applied to oxygen data from cruise 74DI19940219 based on five crossovers that show a small and coherent offset $(0.991 \pm 0.004)$.

Four cruises, not evaluated in the inversion, are also identified for oxygen correction: 49ZS19921203 and three OISO cruises (35MF19981205, 35MF20000117, 35MF20040103). Since the corrections proposed are based on good evidence (for each cruise at least four crossovers are found with cruises that are thought to have good oxygen values), the corresponding adjustments are applied to these cruises (Table 2).

No adjustment is applied to the three INDIGO cruises based on the result of the regional analysis, in good agreement with the result of the inversion as well as the GLODAP corrections. For INDIGO2, the only crossover found in the dataset (crossover with BEAGLE, Leg 5) suggests that a small correction could be required for oxygen $(0.992 \pm$ 
0.006). However, one crossover is insufficient to identify a correction (NC in Table 2).

\subsubsection{Final inversion - oxygen}

Based on the initial crossover analysis, oxygen data from fourteen cruises were adjusted prior to the final analysis: 09AR19960822 (0.96), 09AR20011029 (0.98), 35MF19981205 (0.99), 35MF20000117 (1.06), 35MF20040103 (1.01), 49HH20011208 (1.04), 49ZS19921203 (0.98) and 61TG20020206 (0.97) and the GLODAP cruises 06AQ19960317 (1.01), 74DI19930206 (0.96), 74DI19940219 (1.01), 09AR19930404 (1.03), 09FA19930624 (0.99) and 09AR19910925 (1.02). The final inversion still suggests significant corrections for eight cruises (two of which had already been adjusted as mentioned above): 74DI20041103, 74DI20041213, 35MF20030123, 49ZS19921203 (adjusted), 35MF19960220, 74DI19930206 (adjusted), 74DI19950106 and INDIGO (Fig. 3g). For six of these cruises the final inversion suggests correction factors ranging from 1.010 to 1.017 (74DI20041103, 74DI20041213, 35MF19960220, 74DI19930206, 74DI19950106 and INDIGO), but most of the crossovers used for the final inversion show no significant offsets. Thus it is likely that the results of the final inversion are biased for oxygen, as already suggested for silicate. Table 5 shows that the mean of all corrections proposed by the final inversion for cruises in the Indian sector is $1.005 \pm 0.008$. Nonetheless a bias is not obvious in the global Southern Ocean mean (Table 4), which suggests that it is localized in the Indian sector. In addition, the six cruises for which significant corrections are proposed by the final inversion are all in the eastern side of the basin, close to the Indian-Atlantic boundary, where deep eddies have been observed (Lo Monaco et al., 2005a). Consequently, and because strong evidence support the initial results, no change is made in Table 2 for these six cruises.

For cruise 35MF20030123 mentioned above, no adjustment was applied after the first check based on the result of the regional analysis, whereas the final inversion suggests a correction factor of $0.983( \pm 0.005)$ (based on three crossovers re-evaluated after data correction that show offsets of 1.01 to 1.02 with cruises 09AR19941213, 09AR19960822 and 09AR20011029). However, only a few samples were collected in deep waters during cruise 35MF20030123, which could have biased the inversion. For this reason continuous oxygen profiles recorded during the cruise were fitted to measured oxygen data and used to compare to the three cruises mentioned above. Since no significant offset was detected, in good agreement with the result of the regional analysis, no change is made in Table 2. For cruise 49ZS19921203, the new inversion suggests a correction factor of $1.021( \pm 0.005)$ to correct for the one already applied (0.98). However, this result is based on one crossover only (with cruise 320619960503), whereas the initial adjustment was deduced from eight crossovers (including five reliable crossovers with cruises that are thought to have good oxygen data that show offsets ranging from 0.974 to 0.992 ). For this reason no change is made to the initial adjustments (Table 2).

\section{Data coherence}

CARINA and GLODAP cruise data were first adjusted based on the initial crossover analysis presented in the previous section. A new global Southern Ocean inversion was then performed in order to evaluate the coherence of the adjusted CARINA-GLODAP merged dataset. The results of the final inversion for cruises in the Indian sector are compared to those proposed before data correction in Fig. 3. This shows a good improvement in data consistency for salinity, $\mathrm{TCO}_{2}$ and alkalinity, but the new inversion still suggests significant offsets in nutrients and oxygen for a relatively large amount of cruises. A detailed analysis of these results showed that in many cases the remaining offsets are found where the previous inversion and the regional analysis disagreed (Sect. 4).

The overall improvement in data consistency can be appreciated by comparing the standard deviation around the mean of all corrections proposed by the inversion before and after data adjustment (Table 4). The clear reduction in the standard deviation indicates that the largest offsets have been corrected for. For silicate, the standard deviation is still large after data correction, which could suggest that major offsets remain in the adjusted dataset, but the inability of the final inversion to correctly resolve adjustments for silicate might also be the cause. Evidence for this comes from the mean of all corrections proposed by the inversion (Table 4): a mean correction of 1.014 is found for silicate after data adjustment, whereas it is very close to 1 for the other multiplicative cases (nitrate, phosphate and oxygen) and close to zero for additive cases (salinity, $\mathrm{TCO}_{2}$ and alkalinity). The reason might be that particularly large horizontal gradients are observed for silicate in the deep Southern Ocean, which causes substantial differences in crossover results made at different horizontal length scales (Tanhua et al., 2009).

The overall accuracy of the merged CARINA-GLODAP Southern Ocean dataset was evaluated when the final adjustments are applied (Table 2). We calculated the weighted mean (WM) for each parameter using the absolute value of the offset $(D)$ of $L$ crossovers with the uncertainty $(\sigma)$, as follows:

$$
\mathrm{WM}=\frac{\sum_{i=1}^{L} D(i) /\left(\sigma(i)^{2}\right.}{\sum_{i=1}^{L} 1 /\left(\sigma(i)^{2}\right.}
$$

Based on this analysis, the accuracy of the merged Southern Ocean dataset is 0.002 for salinity, $2.3 \mu \mathrm{mol} / \mathrm{kg}$ for $\mathrm{TCO}_{2}$, $5.1 \mu \mathrm{mol} / \mathrm{kg}$ for alkalinity, $0.8 \%$ for oxygen, $1.1 \%$ for nitrate, $1.3 \%$ for phosphate and $1.2 \%$ for silicate (Fig. 4). 

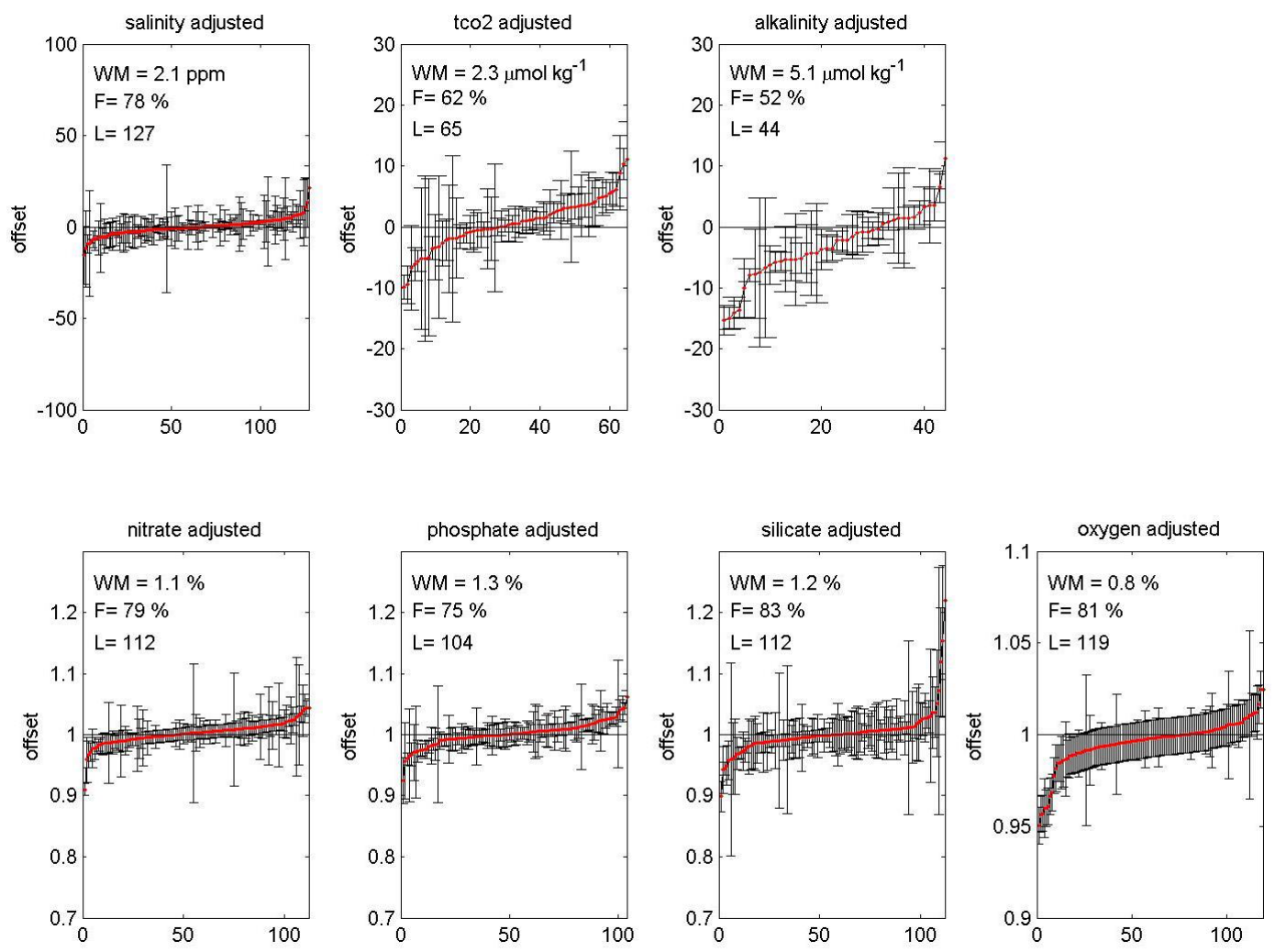

Figure 4. Offsets calculated for the crossovers in the merged CARINA-GLODAP Southern Ocean dataset after adjustments have been applied (Table 2). WM is the weighted mean calculated for each parameter using the absolute value of the offset $(D)$ of all crossovers $(L)$ with the uncertainty $\sigma$ (error bar), according to Eq. (2). $F$ is the percentage of offsets indistinguishable from 1 (multiplicative) or 0 (additive) within their uncertainty and $L$ is the number of crossovers.

\section{Concluding remarks}

The final adjustments reported for CARINA cruises in Table 2, together with those in the Atlantic and Pacific sector of the Southern Ocean, the North Atlantic, the Arctic Ocean and the Nordic Seas (Hoppema et al., 2009; Sabine et al., 2009; Tanhua et al., 2009; Jutterström et al., 2009 and Olsen et al., 2009, respectively) were used to construct a consistent merged dataset (Key et al., 2009). All CARINA data (reported data and the adjusted dataset) are available on the CARINA website (http://cdiac.ornl.gov/oceans/ CARINA/Carina_inv.html). Reported data and their flags are stored in the individual cruise files. In many cases more parameters can be found in these files than have been included in the second quality control (essentially transient tracers, such as ${ }^{14} \mathrm{C},{ }^{13} \mathrm{C}$ and $\mathrm{SF}_{6}$ ). There are no calculated or interpolated values in the individual cruise files and no adjustments have been applied. Conversely, the merged CARINA data file, where adjustments were applied, includes interpolated values for salinity, nutrients and oxygen if those data are missing and if interpolation can be made according to criteria described in Key et al. (2009). Also included in this file are calculated carbon parameters (i.e. if $\mathrm{TCO}_{2}$ and alkalinity were measured, $\mathrm{pH}$ and $p \mathrm{CO}_{2}$ have been calculated). Interpolated or calculated data have been flagged 0 in the merged data file.

Some of the data included in the CARINA data product (merged data file) were not corrected because we could not provide sufficient evidence for an adjustment. For the Indian sector, in addition to $\mathrm{pH}, p \mathrm{CO}_{2}$ and transient tracers data not included in this study, some data were not evaluated due to the lack of measurements for comparison (cruise 09FA1994112), or insufficient evidence for or against an adjustment (NC in Table 2). Some relatively large uncertainties remain in particular regions for certain parameters. In the Indian sector, two regions were identified where ocean variability can have a substantial impact on deep water properties, generating noise in the data: i) near $50-60^{\circ} \mathrm{S}$ due to large horizontal gradients at depth, and ii) around $40^{\circ} \mathrm{S}$ at the Indian-Atlantic boundary where numerous deep eddies have been observed (e.g. Lo Monaco et al., 2005a). Most discrepancies compared to GLODAP corrections were found in these regions (Fig. 3, in particular cruises 06AQ19960317, 35MF19960220, 35MF19930123, 74DI19950106, 7DI19940219). Inconsistencies were also found south of $50^{\circ} \mathrm{S}$, when comparing historical data 
(GEOSECS and INDIGO) with recent measurements, and attributed to ocean variability that can significantly impact deep waters properties over the decadal scale. Consequently, for GEOSECS and INDIGO, the decision for or against an adjustment was based mainly on the crossovers in the subtropical region where more coherent results were found. This could also explain some disagreements with GLODAP, notably for the INDIGO cruises.

The methods used in our analysis have proven their ability to detect offsets in a large dataset and to deduce the adjustments required to improve internal consistency of the dataset. A few questions remain for the cruise/data Not Considered (NC) in Table 2, that can be answered when new data are available. Two important recommendations arise from this work, in order to reduce the uncertainty of the proposed corrections and to facilitate the process of quality control for the next data synthesis: i) we strongly encourage the use of certified reference materials for nutrient measurements in the future and ii) future work also needs to devise sampling strategies to repeat as many deep stations as possible. It is our hope that the analysis presented here, combining historical and modern data assembled in two different databases (GLODAP and CARINA), enable the evaluation and understanding of the changes that occurred in the ocean over the last few decades in relation to human and climatic perturbations.

Acknowledgements. This work has been funded as part of the EU project CARBOCEAN (no. 511176; GOCE), and additional support from the International Ocean Carbon Coordination Project IOCCP (Maria Hood) and the Hanse Institute for Advanced Study (HWK Delmenhorst, Germany). Without the dedication of all investigators and analysts who performed measurements, sometimes under adverse conditions, and contributed their data to the CARINA data base, this project would not have been possible. Support for R. M. Key and X. Lin was primarily from NOAA grant NA08OAR4320752 and NA08OAR4310820. Support for M. Álvarez was from grant RYC-2006-001836. B. Tilbrook was supported though the Australian Climate Change Science Program and the Antarctic Climate and Ecosystem CRC. A. F. Rios and A. Velo also acknowledge support from PGIDIT05OXIC40203PM Xunta de Galicia and CTM2006-27116-E/MAR MEC.

Edited by: A. Olsen

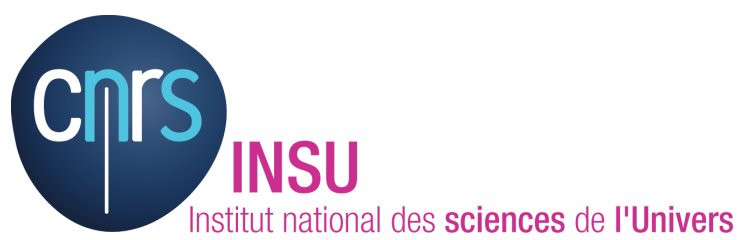

The publication of this article is financed by CNRS-INSU.

\section{References}

Álvarez, M., Lo Monaco, C., Tanhua, T., Yool, A., Oschlies, A., Bullister, J. L., Goyet, C., Metzl, N., Touratier, F., McDonagh, E., and Bryden, H. L.: Estimating the storage of anthropogenic carbon in the subtropical Indian Ocean: a comparison of five different approaches, Biogeosciences, 6, 681-703, 2009, http://www.biogeosciences.net/6/681/2009/.

Bakker, D. C. E., Nielsdóttir, M. C., Morris, P. J., Venables, H. J., and Watson, A. J.: The island mass effect and biological carbon uptake for the subantarctic Crozet Archipelago, Deep-Sea Res. II, 54, 2174-2190, doi:10.1016/j.dsr2.2007.06.009, 2007.

Feely, R. A., Sabine, C. L., Lee, K., Millero, F. J., Lamb, M. F., Greeley, D., Bullister, J. L., Key, R. M., Peng, T. H., Kozyr, A., Ono, T., and Wong, W. S.: In-situ calcium carbonate dissolution in the Pacific Ocean, Global Biogeochem. Cy., 16(4), 1144 doi:10.1029/2002GB001866, 2002.

Gouretski, V. V. and Jancke, K.: Systematic errors as the cause for an apparent deep water property variability: global analysis of the WOCE and historical hydrographic data, Progr. Oceanog., 48, 337-402, 2001.

Hoppema, M., Velo, A., van Heuven, S., Tanhua, T., Key, R. M., Lin, X., Bakker, D. C. E., Perez, F. F., Ríos, A. F., Lo Monaco, C., Sabine, C. L., Álvarez, M., and Bellerby, R. G. J.: Consistency of cruise data of the CARINA database in the Atlantic sector of the Southern Ocean, Earth Syst. Sci. Data, 1, 63-75, 2009, http://www.earth-syst-sci-data.net/1/63/2009/.

Jabaud, A., Metzl, N., Brunet, C., Poisson, A., and Schauer, B.: Variability of the Carbon Dioxide System in the Southern Indian Ocean $\left(20^{\circ} \mathrm{S}-60^{\circ} \mathrm{S}\right)$ : the impact of a warm anomaly in austral summer 1998, Global Biogeochem. Cy., 18(1), GB1042, doi:10.1029/2002GB002017, 2004.

Johnson, G. C., Robbins, P. E., and Hufford, G. E.: Systematic adjustments of hydrographic sections for internal consistency, J. Atmos. Ocean. Tech., 18, 1234-1244, 2001.

Jutterström, S., Anderson, L. G., Bates, N. R., Bellerby, R., Johannessen, T., Jones, E. P., Key, R. M., Lin, X., Olsen, A., and Omar, A. M.: Arctic Ocean data in CARINA, Earth Syst. Sci. Data Discuss., 2, 281-308, 2009,

http://www.earth-syst-sci-data-discuss.net/2/281/2009/.

Key, R. M., Tanhua, T., Olsen, A., Hoppema, M., Jutterström, S., Schirnick, C., van Heuven, S., Kozyr, A., Lin, X., Velo, A., Wallace, D. W. R., and Mintrop, L.: The CARINA data synthesis project: introduction and overview, Earth Syst. Sci. Data Discuss., 2, 579-624, 2009,

http://www.earth-syst-sci-data-discuss.net/2/579/2009/.

Key, R. M., Kozyr, A., Sabine, C. L., Lee, K., Wanninkhof, K., Bullister, J. L., Feely, R. A., Millero, F. J., Mordy, C., and Peng, T. H.: A global ocean carbon climatology: Results from Global Data Analysis Project (GLODAP), Global Biogeochem. Cy., 18, GB4031, doi:10.1029/2004GB002247, 2004.

Lamb, M. F., Sabine, C. L., Feely, R. A., Wanninkhof, R., Key, R. M., Johnson, G. C., Millero, F. J., Lee, K., Peng, T.-H., Kozyr, A., Bullister, J. L., Greeley, D., Byrne, R. H., Chipman, D. W., Dickson, A. G., Goyet, C., Guenther, P. R., Ishii, M., Johnson, K. M., Keeling, C. D., Ono, T., Shitashima, K., Tilbrook, B., Takahashi, T., Wallace, D. W. R., Watanabe, Y., Winn, C., and Wong, C. S.: Consistency and synthesis of Pacific Ocean $\mathrm{CO}_{2}$ survey data, Deep-Sea Res. II, 49, 21-58, 2003. 
Lo Monaco, C., Metzl, N., Poisson, A., Brunet, C., and Schauer, B.: Anthropogenic $\mathrm{CO}_{2}$ in the Southern Ocean: Distribution and inventory at the Indian-Atlantic boundary (World Ocean Circulation Experiment line I6), J. Geophys. Res., 110, C06010, doi:10.1029/2004JC002643, 2005a.

Lo Monaco, C., Goyet, C., Metzl, N., Poisson, A., and Touratier, F.: Distribution and inventory of anthropogenic $\mathrm{CO}_{2}$ in the Southern Ocean: Comparison of three data-based methods, J. Geophys. Res., 110, C09S02, doi:10.1029/2004JC002571, 2005b.

Metzl, N.: Decadal increase of oceanic carbon dioxide in Southern Indian Ocean surface waters (1991-2007), Deep-Sea Res. II, 56, 8-10, 607-619, doi:10.1016/j.dsr2.2008.12.007, 2009.

Mikaloff Fletcher, S. E., Gruber, N., Jacobson, A. R., Doney, S. C., Dutkiewicz, S., Gerber, M., Follows, M., Joos, F., Lindsay, K., Menemenlis, D., Mouchet, A., Muller, S. A., and Sarmiento, J. L.: Inverse estimates of anthropogenic $\mathrm{CO}_{2}$ uptake, transport, and storage by the ocean, Global Biogeochem. Cy., 20, GB2002, doi:10.1029/2005GB002530, 2006.

Mikaloff Fletcher, S. E., Gruber, N., Jacobson, A. R., Doney, S. C., Dutkiewicz, S., Gerber, M., Follows, M., Joos, F., Lindsay, K., Menemenlis, D., Mouchet, A., Muller, S. A., and Sarmiento, J. L.: Inverse estimates of the oceanic sources and sinks of natural $\mathrm{CO} 2$ and the implied oceanic carbon transport, Global Biogeochem. Cy., 21, GB1010, doi:10.1029/2006GB002751, 2007.

McNeil, B. I., Metzl, N., Key, R. M., Matear, R. J., and Corbiere, A.: An Empirical Estimate of the Southern Ocean air-sea $\mathrm{CO}_{2}$ flux, Global Biogeochem. Cy., 21, GB3011, doi:10.1029/2007GB002991, 2007.

McNeil, B. I., Matear, R. J., Key, R. M., Bullister, J. L., Sarmiento, J. L.: Anthropogenic $\mathrm{CO} 2$ uptake by the ocean based on the global dataset, Science, 299, 235-239, 2003.

Olsen, A., Key, R. M., Jeansson, E., Falck, E., Olafsson, J., van Heuven, S., Skjelvan, I., Omar, A. M., Olsson, K. A., Anderson, L. G., Jutterström, S., Rey, F., Johannessen, T., Bellerby, R. G. J., Blindheim, J., Bullister, J. L., Pfeil, B., Lin, X., Kozyr, A., Schirnick, C., Tanhua, T., and Wallace, D. W. R.: Overview of the Nordic Seas CARINA data and salinity measurements, Earth Syst. Sci. Data, 1, 25-34, 2009,

http://www.earth-syst-sci-data.net/1/25/2009/.

Orr, J. C., Maier-Reimer, E., Mikolajewicz, U., Monfray, P., Sarmiento, J. L., Toggweiler, J. R., Taylor, N. K., Palmer, J., Gruber, N., Sabine, C. L., Le Quéré C., Key, R. M., and Boutin, J.: Estimates of anthropogenic carbon uptake from four threedimensional global ocean models, Global Biogeochem. Cy., 15, 43-60, 2001.

Sabine, C. L., Hoppema, M., Key, R. M., Tilbrook, B., van Heuven, S., Lo Monaco, C., Metzl, N., Ishii, M., Murata, A., and Musielewicz, S.: Assessing the internal consistency of the CARINA data base in the Pacific sector of the Southern Ocean, Earth Syst. Sci. Data Discuss., 2, 555-578, 2009,

http://www.earth-syst-sci-data-discuss.net/2/555/2009/.
Sabine, C. L., Key, R. M., Kozyr, A., Feely, R. A., Wanninkhof, R., Millero, F. J., Peng, T.-H., Bullister, J. L., and Lee, K.: Global Ocean Data Analysis Project: Results and Data, ORNL/CDIAC145, NDP-083. Carbon Dioxide Information Analysis Center, Oak Ridge National Laboratory, US Department of Energy, Oak Ridge, Tennessee, 110 pp., 2005.

Sabine, C. L., Feely, R. A., Gruber, N., Key, R. M., Lee, K., Bullister, J. L., Wanninkhof, R., Wong, C. S., Wallace, D. W. R., Tilbrook, B., Millero, F. J., Peng, T.-H., Kozyr, A., Ono, T., and Rios, A. F.: The oceanic sink for anthropogenic $\mathrm{CO}_{2}$, Science, 305, 367-371, 2004.

Sabine, C. L., Key, R. M., Johnson, K. M., Millero, F. J., Poisson, A., Sarmiento, J. L., Wallace, D. W. R., and Winn, C. D.: Anthropogenic $\mathrm{CO}_{2}$ inventory of the Indian Ocean, Global Biogeochem. Cy., 13, 179-198, 1999.

Sallée, J.-B., Speer, K., and Morrow, R.: Response of the Antarctic Circumpolar Current to Atmospheric Variability, J. Climate, 21, 3020-3039, doi:10.1175/2007JCLI1702.1, 2008.

Tanhua, T., van Heuven, S., Key, R. M., Velo, A., Olsen, A., and Schirnick, C.: Quality control procedures and methods of the CARINA database, Earth Syst. Sci. Data Discuss., 2, 205-240, 2009, http://www.earth-syst-sci-data-discuss.net/2/205/2009/.

Tanhua, T., Steinfeldt, R., Key, R. M., Brown, P., Gruber, N., Wanninkhof, R., Perez, F., Körtzinger, A., Velo, A., Schuster, U., van Heuven, S., Bullister, J. L., Stendardo, I., Hoppema, M., Olsen, A., Kozyr, A., Pierrot, D., Schirnick, C., and Wallace, D. W. R.: Atlantic Ocean CARINA data: overview and salinity adjustments, Earth Syst. Sci. Data, 2, 17-34, 2010, http://www.earth-syst-sci-data.net/2/17/2010/.

Uchida, H. and Fukasawa, M. (Eds.): WHP P6, A10, I3/I4 Revisit Data Book: Blue Earth Global Expedition 2003 (BEAGLE2003), Vol. 1-3,JAMSTEC, Yokosuka, Kanagawa, 2005.

Vázquez-Rodríguez, M., Touratier, F., Lo Monaco, C., Waugh, D. W., Padin, X. A., Bellerby, R. G. J., Goyet, C., Metzl, N., Ríos, A. F., and Pérez, F. F.: Anthropogenic carbon distributions in the Atlantic Ocean: data-based estimates from the Arctic to the Antarctic, Biogeosciences, 6, 439-451, 2009, http://www.biogeosciences.net/6/439/2009/.

Wanninkhof, R., Peng, T.-H., Huss, B., Sabine, C. L., and Lee, K.: Comparison of inorganic carbon system parameters measured in the Atlantic Ocean from 1990 to 1998 and recommended adjustments, ORNL/CDIAC-140, 43 pp., Carbon Dioxide Inf. Anal. Cent., Oak Ridge Natl. Lab., Oak Ridge, Tenn., 2003.

Waugh, D. W., Hall, T. M., McNeil, B. I., Key, R., and Matear, R. J.: Anthropogenic $\mathrm{CO}_{2}$ in the oceans estimated using transittime distributions, Tellus, 58B, 376-390, doi:10.1111/j.16000889.2006.00222.x, 2006. 